\title{
The Future of Math Teacher Professional Learning
}

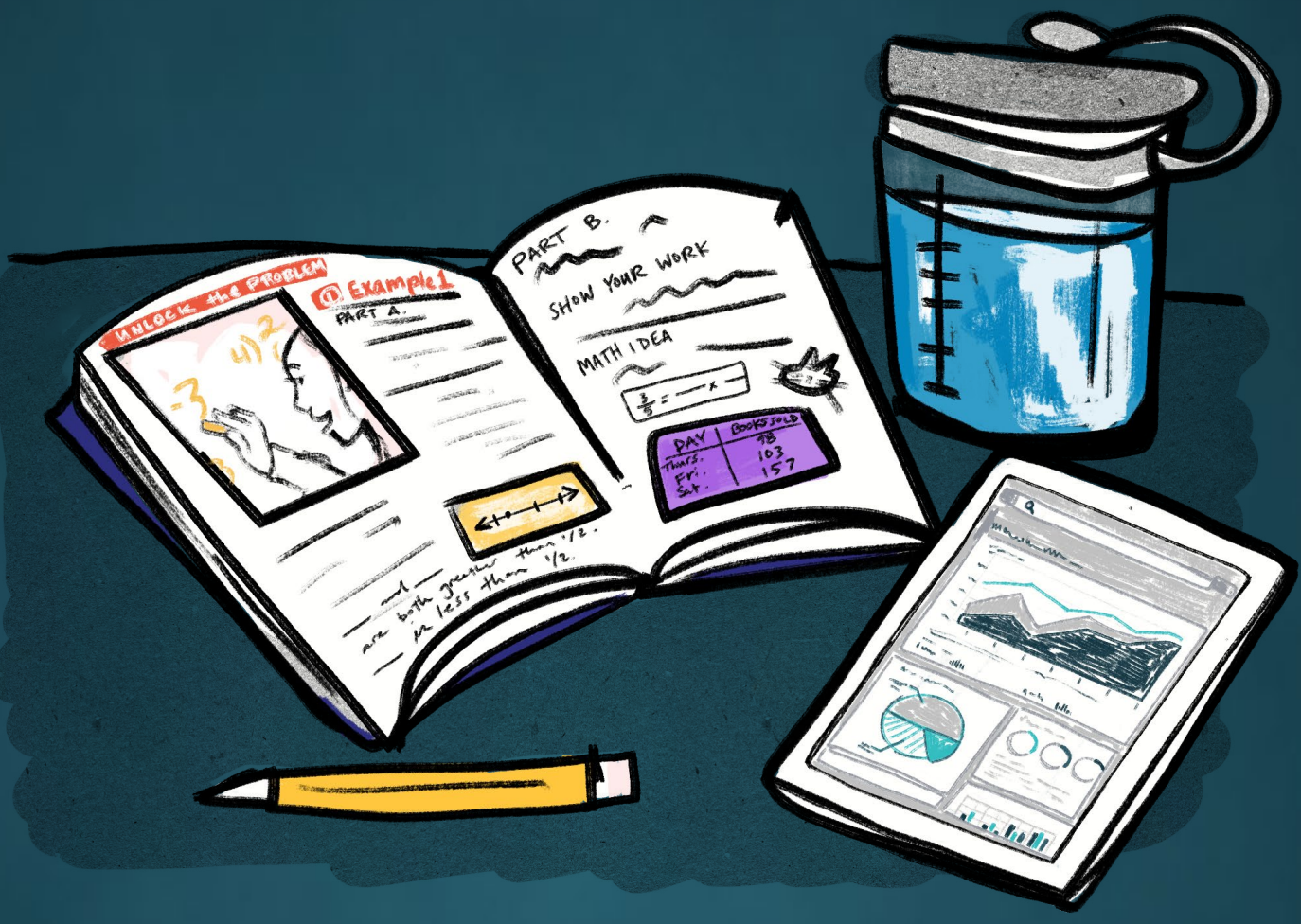

\section{October 2021}

Rachel Slama, Roya Moussapour, Gregory Benoit, Nancy Anderson, and Justin Reich

\section{IIII}

Suggested Citation:

Slama, R., Moussapour, R., Benoit, G., Anderson, N., \& Reich, J. (2021, October 13).

The Future of Math Teacher Professional Learning. Retrieved from http://edarxiv.org/kncs 9

Images by:

Haley McDevitt I haleymcdevitt.com

Kay Dugan Murrell | https://kayduganmurrell.myportfolio.com/work 


\section{Contents}

Executive Summary

Key Findings

Reimagining the Future of Math Teacher Learning

The Challenges Facing Math Teachers and Math Reforms

Activities: A Field-Based Inventory of Math Teacher Professional Learning

Findings: The Steady State, Surges, and Points of Light

Refocusing Professional Learning Communities on Deepening Math Instructional Practice

Professional Learning Tied to Rigorous Math Pedagogical

Content Learning

Instructional Coaching

The Best of the "Steady State": Comprehensive Reform

Teacher-led Professional Learning Innovations

Teacher Pipeline Initiatives

Practice-embedded Teacher Learning Models

Digital Clinical Simulations

Transitioning Movements in Mathematics Education to Teacher Learning

Professional Learning Initiatives Focusing on Equitable Mathematics

New Course Development and Curriculum Innovation 


\section{Executive Summary}

In Summer 2020, the INSPIRE-Math team at the MIT Teaching Systems Lab (MIT TSL) launched a professional learning landscape scan, The Future of Math Teacher Professional Learning. While most math education reform and improvement naturally focuses on students as learners, the best educational systems also attend to the needs of teachers and educators as learners. Our task was to investigate the landscape of how in-service math teachers most commonly learn, what areas of experimentation and innovation exist within teacher professional learning, and how in-service math teacher learning might be improved in the years ahead.

In alignment with priorities of our sponsors, the Bill \& Melinda Gates Foundation, we were particularly interested in understanding promising levers in math teacher professional learning for improving middle years math outcomes for grades 3-9 students who are Black, Latinx, Indigenous, students of color, students experiencing poverty, girls, multilingual students and those who have been traditionally marginalized from the math classroom. Two assumptions underpinning this work are: (1) as a field, we have work to do to drive ambitious and inclusive math teaching and learning, and (2) we are most concerned about students marginalized by the education system.

To conduct our research, we spoke with leading math researchers, educators, department heads, teachers, and curriculum designers. We conducted 25 interviews, and we hosted a virtual convening on math teacher learning that brought together 33 panelists and approximately 170 participants. We asked the following kinds of questions of our interviewees: what does the current state of math teacher learning look like? What are promising future directions for improving math teacher learning in service of better math learning for students?

\section{Key Findings}

From these interviews and conversations, we had five key findings. First, math teacher learning is in what we call a "steady state," where schools and districts generally use three approaches to support math educators: professional learning communities (PLCs), instructional coaching, and professional learning workshops. Second, neither the evidence base supporting the effectiveness of these approaches nor the general educator support for these approaches is particularly strong. Few educators believe that the current usage of the tools of the "steady state" will lead to improved math outcomes. Further, of the three approaches, only coaching has high quality research evidence of effectiveness, and that evidence is mixed, showing benefits for teachers but not subsequent positive outcomes on students.

Third, while the evidence on PLCs, coaching, and workshops is discouraging individually, we do find evidence that comprehensive programs that apply several of these approaches simultaneously with sufficient supports can improve math outcomes for students. We call these comprehensive approaches "surges" of support, and while there is some evidence of their effectiveness, they typically depend on external financial support, and when the external support declines, some of the gains dissipate.

Our final two findings look beyond the steady state. Our fourth major finding is that there are relatively few new approaches to math teacher learning on the research and development horizon. We find a few "points of light" of innovative new approaches, but there is not an extensive, field-wide body of efforts to improve math teacher learning. This is in contrast with a key point from our fifth major finding: math education broadly is quite dynamic with multiple actors pursuing exciting new approaches to math teaching and learning. We suggest that important efforts in math education-such as new approaches to centering issues of equity or new courses and pathways for a computational world-could benefit from greater attention to how these new efforts have implications for math teacher learning. 


\section{Reimagining the Future of Math Teacher Learning}

In our conclusion, we detail a thread of important critiques of our report. As we concluded our research project, we sent a draft of this report out to a number of "critical friends," several of whom argued that our report had deficiencies in our framing. Many of the challenges in the current math teacher learning landscape are rooted in deep-seated structural issues such as how we organize schools for learning, how teachers are viewed as professionals, how the work lives of teachers are organized, and how many schools and systems perpetuate deficit views of teachers and students. Our critical friends expressed that this report insufficiently attended to these structural issues, and we outline their concerns in our final paragraphs.

Below, we summarize our key research activities and findings and provide recommendations for the future of math teacher professional learning. Our report points to best practices that build on traditional professional learning structures and also highlights more novel approaches. Our findings and feedback from the field suggest two overarching principles of improving math teaching and learning. One, there is no magic bullet; systemic math instructional improvement is hard, intense work that requires deep commitment, buy-in, alignment, and resources. Two, many of the challenges in the current math teacher learning landscape are rooted in the deep-seeded structural issues described above.

This report tackles one piece of this puzzle-the more technical professional learning issues that can be addressed with better math teacher learning with a focus on students who have been most underestimated by the system. Future work should continue to press on the contextual factors that mediate what happens when these more "technical" math learning approaches are put into practice. 


\section{The Challenges Facing Math Teachers and Math Reforms}

The task facing math teacher educators is substantial. Three decades of education policy reforms have made great strides in identifying what high quality math teaching, curriculum, and learning should look like. Professional organizations have established ambitious goals for student learning (e.g., Common Core State Standards for Mathematics, 2010; National Council of Teachers of Mathematics [NCTM], 1989,2000 ) which emphasize conceptual understanding and procedural fluency, use of multiple representations, use of argumentation to communicate math ideas, and a student's productive disposition of math.

Working towards these student goals, high quality or ambitious math teaching includes building on student reasoning to solve challenging tasks by launching rigorous math problems, monitoring a range of student solutions, and pressing students to justify their reasoning and connect their solutions to that of their classmates and ultimately, the larger mathematical concepts as they present their ideas to the whole class (e.g., see Gibbons \& Cobb, 2016 for an overview).

Yet, there is compelling evidence that despite large investments in teacher professional learning and standards-aligned curricula, there have only been small improvements in teachers' mathematical knowledge and limited adoption of standards-aligned curriculum materials (Hill, 2021). Building transformative classrooms with ambitious teaching is hard work that requires commitment from teachers and administrators, many of whom do not have a mathematics background or a reform-based view of math education. Transforming math teaching and learning also requires a substantial financial investment.

However, when research-backed, sustained, and systemic approaches tackle math teaching and learning head-on in poverty-impacted schools and districts, students do thrive. We have documented case examples throughout the report where comprehensive programs of math teacher professional development and school-based coaching combined with the adoption of a standards-aligned, inquirybased curriculum and formative math assessments resulted in large student instructional gains. For instance, in Boston, after substantial targeted math teacher learning and curricular investments, the number of students passing the fourth grade math assessment jumped from 56 percent to 77 percent and national assessments targeting improvements in urban schools showed Boston leading the pack in the biggest math improvements from 2003 to 2007 among 10 large urban districts (Grant \& Davenport, 2009). There is emerging evidence that in some cases, some of these gains are sustained after the period of funding, although challenges such as teacher turnover and shifting focus on competing school priorities may damper such lasting gains.

\section{Activities: A Field-Based Inventory of Math Teacher Professional Learning}

To better understand the challenges facing the future of the math teaching profession, we led a series of research and dissemination activities to engage a broad range of thought leaders in service of the following goals:

- Understand the state of the math professional learning field today

- Define the problem and opportunity areas for supporting mathematics teacher learning

- Generate a series of hypotheses on how to strengthen math teacher knowledge and skills with a focus on middle years math learners most underestimated by the education system 
This math teacher professional learning landscape scan consisted of several activities: (a) canvassing a range of voices in math education; educators who have taken a professional learning leadership role on social media, leaders from professional learning organizations, district coaches and department leaders, and math teacher education researchers about promising directions for math teacher professional learning, (b) engaging the math professional learning community online through a twopart virtual conference, The Future of Math Teacher Professional Learning, (c) conducting a brief literature scan of secondary data sources to gather background information about math teachers in the U.S. and common frameworks for math teacher learning, and (d) publishing and disseminating knowledge to the field.

In our engagement with educators, researchers and the literature, three practices emerged most frequently as the most common approaches to in-service professional learning for math teachers: PLCs, instructional coaches and math specialists, and professional development related to content knowledge and pedagogical content knowledge. In the next section, we review key features of these common practices when they are working well, with the caveat that individually, they are not always up to the task of improving math outcomes for all learners.

\section{Findings: The Steady State, Surges, and Points of Light}

Overall, our assessment is that the field of in-service math teacher learning is in a "steady state." Math educators report a set of approaches to professional learning that have largely remained unchanged over several decades, despite limited success at improving math teaching and learning. Educators in schools and districts report three core approaches to math professional learning: professional learning communities or PLCs, instructional coaching, and professional development around math content and pedagogical content knowledge. These steady state interventions can be powerful learning opportunities for educators when done well with sufficient funding and strategic leadership, but overall they do not appear to be up to the task of supporting the kinds of continuous improvement in math teaching that could make a substantial impact on opportunities and outcomes for all learners.

To be clear, steady is not always a good thing. While "steady" references a greater standardization of practice, steady can indicate a level of complacency in the field and an unacceptable tolerance of insufficient and inequitable opportunities and outcomes within math learning. Our view is that the steady state of math teacher learning is not providing the professional learning necessary for the math teaching force to effectively serve all U.S. math learners.

The most powerful applications of PLCs, coaching, and content professional development are when they are applied comprehensively and in tandem, typically in projects that we call "surges." In a handful of districts, there have been substantial programs to use these three core approaches as part of a well-funded, sustained effort to improve mathematics teaching in schools. These more comprehensive efforts have been successful in reducing opportunity and achievement gaps. It is also common that when the supplemental funding ends, learning gains from surges dissipate.

Looking beyond the steady state, there is substantial innovation and experimentation happening in math education broadly, but we did not discover active, well-developed networks of innovation and experimentation in regards to in-service math teacher learning. For this report, we identified four "points of light" that represent a handful of interesting and important early-stage innovation efforts in math teacher learning: teacher-led online professional learning networks, pipeline initiatives to recruit more teachers from local communities, practice-based teacher learning, and digital clinical simulations. 
These various initiatives currently have a relatively small footprint, but they show promise in engaging and developing teacher capacities.

While innovation across in-service math teacher learning is modest, there are many movements within math education that are pushing the field forward on issues such as curriculum quality, mindsets, new courses to meet future labor market and civic needs, and a much-needed focus on equity and inclusion. In our research, we were surprised to find that the theories of change for these movements often involved changing the field without attending closely to changing teacher learning. There may be opportunities to engage these dynamic places in the field of math education and encourage them to put greater attention towards how teacher learning can be an integral part of their change agenda.

Based on these findings about the "steady" but arguably not future-ready state of math teacher learning, we propose four approaches to improve the field:

1. Revitalize specific features of the "steady state": PLCs, instructional coaching, and content-interventions have mixed evidence of efficacy, but they are the common building blocks of math teacher learning throughout the field. Areas of opportunity exist within this "steady state" for innovation, design, and research (e.g., examining why content-focused interventions do not translate into student math gains).

2. Re-energize and re-evaluate "steady-state" suite of approaches: Our research suggests that in its most comprehensive, well-supported forms, the "steady state" suite of approaches can help schools and districts make substantial progress towards supporting all learners. Rather than new innovation, the field may need more urgency in making the best-in-class efforts to find greater support. This could involve advocacy for greater investment in math, training for school and district leaders around starting and sustaining these initiatives, or research in how learning gains from "surges" can be made more sustainable.

3. Spur experimentation and innovation in teacher learning: If we believe that the "steady-state" is not up to the task of nurturing a teaching corps that can lead substantial gains for all learners, then the field may need new approaches. There is not currently a deep bench of innovation and experimentation to draw from. A new fund for seed-stage investments could spark experimentation and innovation, generate new thinking and practice, and launch initiatives that could supplement or replace the steady-state.

4. Encourage important movements in math education to engage more substantially with math teacher learning: Many exciting initiatives within math education propose that math educators teach differently, but few of them deeply engage with math teacher professional learning. We see the movements for greater attention to equitable, inclusive math education and efforts at developing new courses to address a computational world as places with exciting opportunities to rethink in-service math teacher learning. These movements must incorporate explicit professional learning support, or teachers will not change their practice.

In what follows, we describe the steady state of mathematics teacher learning, points of light for new innovation, and areas of dynamism in math education that could place more emphasis on math teacher learning. In each section, we summarize our recommendations and ideas that stem from each initiative or innovation in the form of a "call to action" to different stakeholder groups who might lead the charge on implementing the recommendations that stem from this report. In the Conclusion, we share our broad takeaways for improving math teacher professional learning, and several important critiques of this report from a group of valued colleagues. 


\title{
Refocusing Professional Learning Communities on Deepening Math Instructional Practice
}

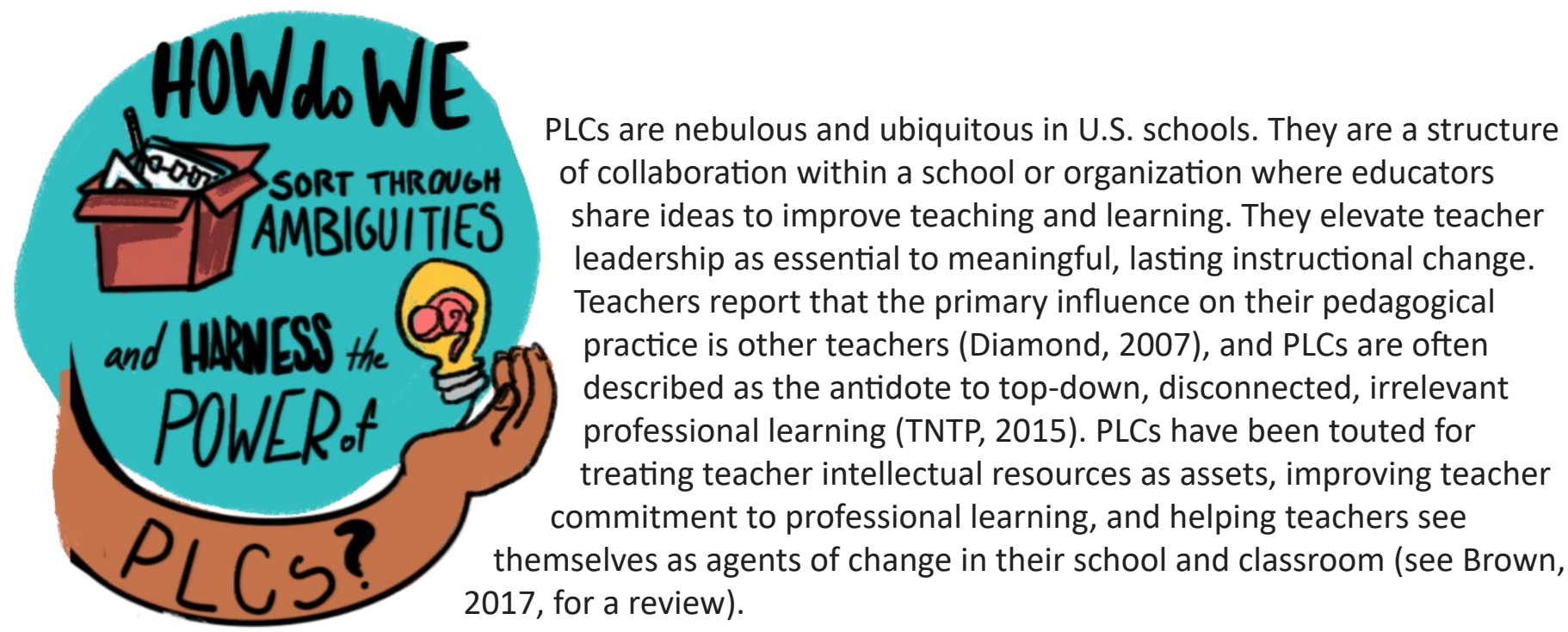

At the same time, PLCs have been plagued by two related challenges. First, the wide diffusion of PLC forms and methods and the variability in implementation has rendered the term basically meaningless. In a PLC, teachers might be co-planning, doing a workshop together, pursuing individual study, or carrying out a principal-led reform effort. Second, PLCs are plagued by the same challenge that most new education reforms face: enthusiasm that quickly fades when new initiatives are widely disseminated, fail to be implemented as intended and then do not lead to the desired results. Education researcher Dufour (2004, p.6) captured this sentiment about PLCs nearly two decades ago:

\begin{abstract}
"In this all-too-familiar cycle, initial enthusiasm gives way to confusion about the fundamental concepts driving the initiative, followed by inevitable implementation problems, the conclusion that the reform has failed to bring about the desired results, abandonment of the reform, and the launch of a new search for the next promising initiative. Another reform movement has come and gone, reinforcing the conventional education wisdom that promises, 'This too shall pass."
\end{abstract}

The term PLC has come to mean so many things, rendering it nearly impossible to document a link to student learning. If PLCs are to be a powerful tool of improving math teaching and learning in the future, the field needs to come together to revisit their purpose, effective structures and routines, and connections with other math reform efforts.

A critical first step to real change for learners underestimated by the system is to engage teachers to critically examine their beliefs and assumptions.

Issues of equity must be tackled head on, helping teachers recognize how societal inequities affect student math learning as well as the role that teachers' own beliefs and assumptions about student capabilities play in learning. One math teacher leader affirmed that teacher beliefs would be one of the very first things to address in teacher learning noting that a large majority of teachers they worked with in one large urban school district had negative views of learners' math abilities which prevented them from imagining how improving instructional practice could drive student math achievement: 
"You can imagine what happens. You show a video or something, but that's those kids. You should see my kids. So for us, that would be one of the very first things you'd want to address in teacher learning. And I don't believe the districts we worked with were in any way abnormal or unusual, which would mean a very high percentage of teachers have relatively negative views of their kids' current capabilities."

PLCs must be organized to show teachers that their students are capable math learners, for example, by collectively selecting rigorous instructional tasks to enact and debriefing the range of math reasoning that students used to solve the task. In the "Call to Action" box below, we identify additional key directions for re-energizing PLCs.

\section{Call to Action}

- Researchers: Use meta analyses and case studies to investigate examples of PLCs that lead to sound and effective practices, and explore which approaches to

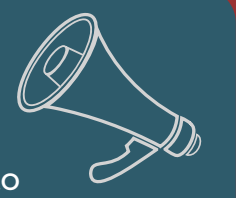
PLCs are most closely linked to improvements in teacher instructional practice, student achievement, and other distal outcomes such as school instructional climate and teacher retention

- Professional learning and advocacy organizations: Convene a dedicated group of math educators and teacher educators through conferences or working groups to redefine and revitalize PLCs, and charge them with the task of bringing structure and focus to our fractal understanding of a widespread, diffuse phenomenon, including building understanding of a math learning progression across grades

- Administrators: Investigate how to balance teachers' agency in tackling problems of instructional math practice with coherent, school and district-wide improvement approaches

- Funders: Sponsor grants to teachers to lead instructional improvement efforts that follow principles of best practice for PLCs with the aim of creating an expert-reviewed repository of math-focused PLC materials by grade band (e.g., sample agendas, sample materials, lesson plans)

\section{Professional Learning Tied to Rigorous Math Pedagogical Content Learning}

Math teacher professional learning experts have largely focused on two areas of research related to teacher content learning: (1) qualifying the mathematical content knowledge of practicing teachers and (2) exploring the relationship between this construct and other classroom factors (e.g., a teacher's work in the classroom and a student's achievement).

Scholars call the knowledge that is needed to effectively teach math, mathematical knowledge for teaching, recognizing that the tasks and decisions involved in teaching mathematics require knowledge of mathematics beyond broad pedagogical skills. Mathematical knowledge for teaching includes tasks such as explaining terms and concepts to students, interpreting students' statements and solutions, judging and correcting treatments of particular topics in textbooks, using representations accurately in the classroom, and providing students with examples of mathematical concepts, algorithms, or proofs 
(Hill et al., 2005). To better serve students most underestimated by the system, a growing body of work has highlighted the importance of teachers building on students' strengths, providing rigorous, rich, and relevant curricula, and building stronger community relationships. We unpack these recommendations in more detail below.

A set of studies underscored the pressing need to deepen teachers' mathematical knowledge of teaching (Garet et al., 2016; Hill, 2021). Teachers often bring their own experiences as K-12 math students into their classroom practice. When those experiences rely on a considerable amount of memorization and lack of conceptual knowledge, teachers may struggle to facilitate deep learning experiences for their students. As one interviewee said, "A lot of teachers were not taught in the way that they need to teach now. They don't know the content to the degree that they're supposed to teach it. So, we need to bring that up." This quotation underscores the importance of building teachers' content and pedagogical content knowledge.

Researchers examined the relationship between mathematical knowledge for teaching and a teacher's efficacy in the classroom. Driving this work was the belief that the deeper a teacher's understanding about the work of teaching math to children, the higher the quality of math instruction they will bring to their students (Ball et al., 2008; Hill et al., 2005). Accordingly, we would expect that supporting teachers in learning content knowledge should improve teaching and teacher outcomes. As one panelist noted, "if we want to ensure that students are receiving meaningful classroom experiences, then we have to make sure that their teachers receive meaningful training, both math-specific content and how to use a quality curriculum." However, the research literature does not provide strong evidence between these approaches and improved outcomes (Garet et al., 2011; Garet et al., 2016; Kraft \& Hill, 2020).

The field should unpack this puzzle; math teacher professional learning interventions are built on the premise that better math teaching will lead to improvements in student learning. Why has this link been so difficult to prove? One study participant hypothesized that content-focused interventions have not translated to student learning gains because they lack interactive and constructive methods that teachers can take back to their own classrooms and apply. Other experts point to teachers' low expectations and deficit views of learners and the need for more teacher support around what to do when learners are struggling with a mathematical objective. Another expert hypothesized that studies of the type of deep, sustained professional learning required to promote teacher and student math learning usually direct study funds towards teacher stipends rather than rigorous randomized controlled trials. In other words, the costs of conducting and simultaneously evaluating high quality PD often exceeds the award amounts of grants.

The field should continue to press on the many factors mediating teacher and student math learning. In the meantime, here are a few areas that hold promise for content-focused instructional improvement:

1. Develop teachers' math content knowledge alongside core instructional practices: The work teachers do is complex. Professional learning must acknowledge the many aspects of instruction that teachers juggle while helping teachers improve in specific and effective math practices. However, for teachers with fragile content knowledge, new pedagogy will be very difficult to implement. One interviewee noted: "I think that content knowledge for teaching must come first. And if it doesn't, all these great practices, and if you're using these great practices around mathematics that's not important, then you're wasting students' time."

Another interviewee noted that, "...for a teacher to be able to facilitate meaningful math discussion, they have to know the content themselves to know where it's going." 
Effective professional learning helps teachers dig into the math, examine how students understand the math and how they grow in a particular domain with the goal of creating independent learners.

2. Help teachers gain the content knowledge to view student "mistakes" as valuable clues to develop students' mathematical understanding: New forms of professional learning must help teachers recognize patterns in students' mathematical thinking and be prepared to respond to different student answers in a way that builds students up as critical thinkers. Teachers should view student ideas as clues as to where students are in their mathematical trajectories rather than in an evaluative light of wrong or right. Deep content knowledge is essential for building the bridges between alternate and misconceptions and commonly accepted mathematical practices. One school-based math expert noted:

'It is curiosity about, interest in, and appreciation for students' mathematical reasoning that can help deepen teachers' understanding of the math content and vice versa."

Below, in Exhibit 1, we highlight an example of a teacher professional learning curriculum that aims to deepen teachers' content knowledge and pedagogical content knowledge as an example of the type of intensive work that teachers must engage in to build expertise. An important caveat is that a link between content-focused interventions and student achievement remains tenuous (e.g., Hammerman, Demers, \& Higgins, 2015). Then, we outline several "calls to action" for the field as they related to content-focused teacher learning.

\section{Exhibit 1. Teacher Professional Learning Curriculum Spotlight: Developing Mathematical Ideas (DMI)}

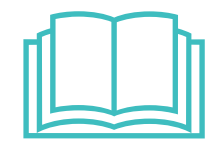

Developing Mathematical Ideas (DMI) is a professional learning curriculum designed to help teachers think through the major ideas of K-8 mathematics and examine how children develop those ideas. At the heart of the materials are sets of classroom episodes illustrating student thinking as described by their teachers. The curriculum offers teachers opportunities to explore mathematics content, to analyze student thinking about that content in written and video cases, to share and discuss the work of their own students, and to read overviews of related research. The materials were developed by the Education Development Center (EDC), Summermath for Teachers at Mt. Holyoke College, and TERC, through a grant to EDC from the National Science Foundation with additional support from Bill and Melinda Gates. Modules include Building a System of Tens; Making Meaning for Operations; Reasoning Algebraically About Operations; Examining Features of Shape; Measuring Space in One, Two, and Three Dimensions; Modeling with Data; and Patterns, Functions, and Change.

Source: https://www.terc.edu/terc products/developing-mathematical-ideas/ 


\section{Call to Action}

- Funders: Support research to better understand the factors that mediate the relationship between teacher math learning, student achievement gains, and the design implications for teacher professional learning interventions

- Researchers, academics and professional learning and advocacy organizations: Identify the content knowledge that has the greatest impact on the work of a teacher or "high leverage content" and assess teachers' gaps in supporting all learners to meet the mathematical objectives

- Administrators: Refocus the school's math instructional improvement conversations on building teachers' curiosity about, interest in, and appreciation for students' mathematical reasoning to help deepen teachers' understanding of the math content

\section{Instructional Coaching}

Content-focused instructional coaching holds promise as a mechanism for improving teacher practice and student learning because it is tailored to the individual teacher, school and culture, can be intensive in focus, and sustained in duration given adequate resources and support.

However, only a small research base has linked math coaching elements to improvements in teacher practice and student math learning. In a randomized controlled trial of a math web-based coaching program, Kraft and Hill (2020) found "sizable and sustained" effects on teachers' ability to analyze instruction and their instructional practice, but no discernable gains in student math achievement. A small but rigorous pilot study (AIR, 2020) found similar encouraging effects on instruction but smaller effects on achievement. Thus, the field stands to learn more about the impact of coaching on teacher practice and importantly, on student math achievement.

Other scholars have identified productive content-focused coaching practices: identifying immediate and long-term goals for teachers' development, assessing teachers' current instructional practices and comparing this to a developmental trajectory towards ambitious teaching, and designing activities that support teachers in moving closer towards desired outcomes (e.g., Gibbons \& Cobb, 2016). Building on this work, our field research suggests several features of effective math coaching programs that should be tested at scale.

1. Get the right coaches in the right places: The nuts and bolts of coach deployment matters. We found widespread agreement that it was important to hire coaches with deep math content expertise, rather than individuals just "slightly ahead" of their peers. Given the depth of support that teachers need to implement ambitious math instruction, it may be difficult to find enough coaches to fill this role. One expert noted:

"One of the difficulties is that teachers need to see dozens and dozens of images of ambitious teaching to even begin to generalize. Then depending on where they are in terms of their own knowledge, they need significant support in trying to implement practices... finding enough coaches with this in light of what teachers need, may not make this a scalable model." 
We found competing claims about where these coaches should be located in the system. Embedding coaches within a school, as opposed to having coaches travel across multiple schools, appears to allow for deeper engagement. But, when coaches are seen as school staff rather than district staff, they are at risk of being reassigned by principals to other tasks like lunch duty. The experts we spoke with noted a tension that may arise between centrally-supervised coaches and school administrators because school leaders may worry that the coaches will be the "eyes and ears" of the district office. Clearly, much trust needs to be built between coaches, administrators, and central office staff to ensure an effective math coaching partnership.

2. Define the coach role, norms for interacting with teachers, and goals for coaches and teachers: In the same way we imagine what strong mathematics teaching practice looks like, we need to ask what a strong mathematics coaching practice might look like. Experts highlight the importance of focusing on productive goals with teachers which means: (a) the goal represents a feasible step for that teacher and (b) if attained, it will likely result in immediate improvements in student learning (for more on defining content-focused math coaching goals, see Gibbons \& Cobb, 2016; Russell et al., 2020).

Our research suggests that the field is shifting towards learning of specific teaching practices and working with content within those specific practices. Coaching should similarly focus on modeling very specific teaching practices (e.g., helping teachers create an effective lesson launch). This can be effective if the teacher has sufficient content knowledge to make in-the-moment instructional decisions improvisationally with students.

A range of less well-explored coaching models should still be tested. One district leader suggested that in resourcestrapped districts, using math coaches to support teacher planning might provide more leverage than having coaches in classrooms with teachers. In a small project where math coaches worked with teacher teams to plan one hour per week, there was anecdotally a strong impact on teaching and learning, even without the coaches being directly present in the classroom. In that case, part of planning for the math lesson involved the teachers and coaches doing the math problems in advance and anticipating how students would respond.

3. Address beliefs and practices together: Effective teaching practices need to be paired with high expectations for students. A key function of coaches is to enact ambitious teaching in teacher's classrooms as a model that teachers can strive to emulate (more on this model in Gibbons et al., 2021). Even when teachers have high expectations for their students, they must also have an image of what ambitious math instruction looks like in practice. As one interviewee noted: 
“...if teachers have high expectations for kids, but they don't have any way of helping kids meet those expectations it's all for naught... if teachers are going to improve, just to get in the game of getting better, they have to have a pretty reasonable image of what high quality teaching looks like. How can you develop a practice, if you haven't got a clue what it looks like? And if you have an image, you have to believe that form of instruction is appropriate for your students."

4. Help administrators understand and fully support the math coach role: To leverage the power of instructional coaches, administrators must be in full support of their role and facilitators of their collaboration with teachers. For instance, administrators can ensure that coach and teacher schedules align so that coaches are present during grade level common planning time meetings, and set expectations for how teachers should work with the coaches. At all costs, coaches should not be repurposed to fill staffing needs such as lunch duty or substitute teaching. More broadly, there is a need to demystify the instructional coach's role, particularly for administrators.

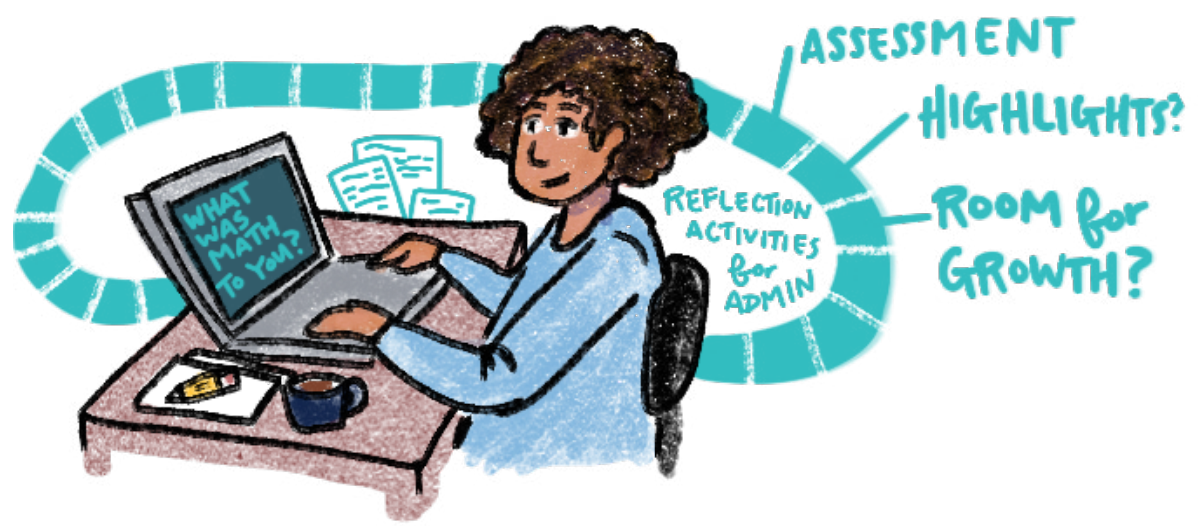

Below, we outline several "calls to action" for the field as they related to content-focused teacher learning.

\section{Call to Action}

- Funders: Explore scalable math coaching models such as a web-based or hybrid coaching academies to prepare coaches with deep expertise in math content and reform-based math practice and place them in schools with large numbers of learners underestimated by the system

- Administrators and researchers: Support districts in maximizing their math instructional resources through audits and analysis to free up funds to hire instructional coaches

- Researchers: Rigorously evaluate the impact of innovative coaching models on teacher practice and student math learning in a range of contexts

- Professional learning and advocacy organizations: Explore and highlight models where coaches supported teachers in building relationships with students and families and document the link to student outcomes

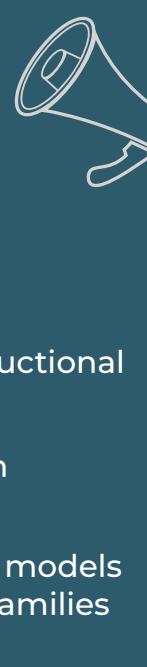




\section{The Best of the "Steady State": Comprehensive Reform}

Individually, the three components of the steady state are quite common, rarely integrated, and have limited evidence of efficacy in improving math experiences and outcomes for all students. Coaching and content-focused professional learning, in their best implementations, improve teacher instructional practice but there is limited evidence of a subsequent improvement in student math learning; PLCs have much less robust evidence of impacting teacher practice or student learning, likely because they have become so diffuse.

When these individual components are integrated into a well-funded, comprehensive program-when they combine into what we call a "surge" of professional learning supports, there is evidence that these programs combined can work. A series of studies over the past decade have shown that pouring the right math technical assistance resources into challenged schools can drive meaningful student gains in mathematics (Chapin \& O'Connor, 2004; Grant \& Davenport, 2009; Silver \& Lane, 1993; Silver \& Stein, 1996).

Here, we highlight one particular example, as both a cautionary and hopeful tale, of what is possible when math teaching and learning are addressed comprehensively. The example reform efforts described here stem from a partnership between the National Science Foundation (NSF) and the Boston Public Schools district that helped teachers engage in intensive math professional learning through a combination of professional learning opportunities totaling more than 100 hours of support for each teacher over the course of the three year program. The project provided additional stipends for out-of-school hours and paid for substitutes for teachers. The district also paid math coaches' salaries and the cost of adoption of the new K-8 curricular materials.

Project staff observed significant student gains on math assessments as well as additional interest and excitement from students around math. After funding for the program ended, the coaching positions were eventually defunded and the professional learning budget shrank. Gains that were made over the course of the program were not sustained to the same degree-in part due to new teachers and administrators who had not been involved in the project. However, according to professional learning leaders involved in the project, some of the changes in instructional practices persisted after the period of funding and teachers reported anecdotally they could never go back to the way they used to teach. This suggests that longer-term shifts to reform-based math instruction are possible with deep and comprehensive professional learning interventions.

When research-backed, systemic approaches tackled math teaching and learning head-on in poverty-impacted schools and districts, students thrived. In some cases, when funding for these programs ultimately runs out and teachers trained under these programs transition out of these districts, the gains made under these programs may disappear. However, in the case of Boston, this leads us to a significant question: have we already figured out how to disrupt the cycle of math underperformance, but just don't fund programs continuously? Perhaps the answer is simple: stop underfunding the coaching, curriculum, and professional development resources required for effective math teacher learning. Below, we provide some suggestions for "calls to action" in this area and unpack them in the Conclusion. 


\section{Call to Action}

- Administrators: Understand factors and mechanisms that can support sustainability of teacher professional learning initiatives

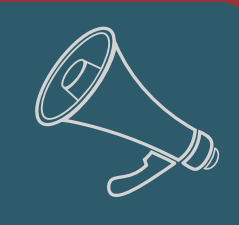

- Funders:

- Invest in research to help district and school leadership make learning gains from surges more sustainable when funding dwindles

- Engage business, tech, and national security sectors around math teacher learning

- Professional learning and advocacy organizations: Raise awareness about past success stories to support advocacy for greater state and municipal investment in math teacher learning 


\section{Innovation and Investment Beyond the Steady State}

After PLCs, content-focused professional learning, and coaching, the landscape of math teacher learning leads into much sparser terrain. In the year 2000, a landscape scan of teacher professional learning might have seen PLCs as a new and growing idea on the horizon of school practice, moving rapidly towards the center. In 2021, there do not appear to be obvious contenders for new elements in the "steady state." We identified at least four "points of light" for innovation in math teacher professional learning -ideas that have shown initial promise but may require additional experimentation and testing in order to recommend future validation studies:

\section{Teacher-led professional learning innovations \\ 2. Teacher pipeline initiatives \\ 3. Practice-embedded teacher learning models \\ 4. Digital clinical simulations}

Below, we describe each "point of light" and provide examples and calls to action.

\section{Teacher-led Professional Learning Innovations}

Our data reveal strong examples of promising teacher-led math professional learning initiatives. We documented cases where teachers relatively quickly developed and implemented new math courses that responded to their student interests and the demands of the future of work such as discrete mathematics, financial literacy, math biology, and data science courses with social-justice oriented inquiry projects. We describe these courses in more detail below in the curriculum innovation section of Transitioning Movements in Mathematics Education to Teacher Learning.

There is also a growing online teacher-led math community which holds promise for catalyzing new professional learning movements including groups organized around Twitter hashtags like \#iteachmath and \#mtbos (the Math Twitter BlogOSphere) and the Global Math Department (Exhibit 2). Math educators reported that they sought out social media to meet their individual professional learning needs to complement district initiatives or because district initiatives did not meet their needs. One educator noted, "I know my engagement on Twitter has supported me more than many district-run PDs." Other organizations such as the Math Teachers' Circle Network (Exhibit 3) have found great success pivoting to an online format during the COVID-19 pandemic. The groups of math educators who actively share math teaching and learning ideas online have a significant number of peer followers and collaborators. We also documented for-profit teacher-led professional online, including self-paced learning opportunities (Exhibit 4).

In Exhibits 2 and 3, we highlight online teacher-led math learning initiatives which are open source opportunities for teachers to connect with other math educators, build a resource library, and 
sharpen their own math content knowledge and build confidence and knowledge for teaching. One important question that future investments should examine is whether these online initiatives translate to classroom practice and if so, do they improve student learning? If not, how might they be adapted to emphasize improvement in math practice?

\section{Exhibit 2. Innovation Spotlight: Global Math Department}

The Global Math Department (GMD) aims to share ideas about teaching and learning mathematics with the teaching community. GMD was started by a group of teachers who are passionate about mathematics and the free sharing of knowledge. GMD has bi-weekly newsletters and teacher-led webinars to help disseminate their information. GMD is also active on Twitter and curates information for their followers through links to different blogs and Twitter threads on their website. The GMD is able to reach a large community of math teachers and can easily grow its online platform. All GMD webinars and newsletters are free and accessible online. The GMD is run entirely by volunteer math educators and continuously includes new volunteers to help grow their programming.

Source: https://globalmathdepartment.org/

\section{Exhibit 3. Innovation Spotlight: Math Teachers' Circle Network}

Math Teachers' Circle Network is a network which creates "circles" of mathematics professionals of K-12 and college level teaching to foster teachers' positive math identities. Now with a network of about 150 circles across the country, the network helps set up

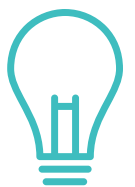
meetings and develop a longer-term funding strategy for the particular circle. Math Teachers' Circle Network allows for professionals of all levels to solve math problems with each other and foster longerterm relationships with members in the community. The goal of the network is to provide insight into different approaches on math teaching while demonstrating different methods across grade levels. The circles provide learning opportunities for teachers and mathematicians to gain insight into each other's profession, culture, and work. The Math Teachers' Circle Network has transitioned to an online format due to the COVID-19 pandemic, but typically holds in-person circles in local communities as well as inperson events at major math conferences across the country.

In a series of observational studies, researchers found that participating in an intensive way in a Math Teachers' Circle was associated with increases in teachers' mathematical knowledge for teaching (White et al., 2013), strengthened teachers' mathematical identities (Hendrickson, 2016), and helped teachers feel more prepared and established in their profession (Marle et al., 2012).

Source: https://www.mathteacherscircle.org/about/what-is-a-math-teachers-circle/

In Exhibit 4, we highlight potential benefits of asynchronous, on-demand professional learning such as Grassroots Workshops, a series of online, self-paced, math professional learning workshops taught by educators. Challenges to this approach include an individualized, "a la carte" approach that may not lend itself to systems-wide or school-wide change. Future work should test how well these approaches are integrated into teachers' individual practice and the extent to which they might influence broader school-wide instructional improvement. 
Exhibit 4. Innovation Spotlight: Grassroots Workshops: Self-Paced, Extended Access, and Differentiated Professional Learning

Grassroots Workshops aim to reimagine math teacher professional learning by creating a menu of flexible and on-demand teacher-led workshops that allow educators to choose "what they learn, who they learn from, and how they learn." Created by a longtime math educator, Grassroots Workshops intentionally responds to many of the challenges of math teacher professional learning. Asynchronous, online options tackle the challenge of teachers finding time in their work day to attend professional learning or spending their time preparing lesson plans for a substitute teacher. Extended access options respond to the notion that meaningful professional learning is sustained over a period of time and not a "one and done" approach to teacher learning.

Source: https://grassrootsworkshops.com/workshops

\section{Call to Action}

- Researchers: Investigate the impact of teacher-led professional learning on instructional practice and student learning and the relative effectiveness of different modes of learning (e.g., asynchronous vs. synchronous; individualized vs. school-wide) on teaching and learning

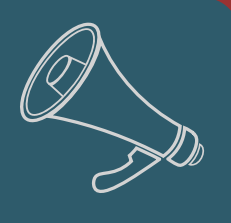

Professional learning and advocacy organizations: Better understand the affordances and constraints of different models of teacher learning (e.g., teacher-led vs. job-embedded) on longer term outcomes such as teacher professional growth, retention, and satisfaction

\section{Teacher Pipeline Initiatives}

U.S. teacher shortages are concentrated in particular subject areas like math, science, and special education, and poverty-impacted districts (Dee \& Goldhaber, 2017). Schools where large percentages of learners are underestimated and marginalized from the education system face the linked problems of school climate and high teacher turnover (Carver-Thomas, \& Darling-Hammond, 2017). This means that the nation's most vulnerable learners are often matched with the most inexperienced, ineffective teachers (see Boyd et al., 2008, for a review).

Some scholars suggest that students of color may fare better academically when they have a teacher of color. Teachers of color can serve as role models, potentially have higher expectations for students from their community, and tend to exhibit less discriminatory disciplinary practices (see Goldhaber et al., 2019 for a review).

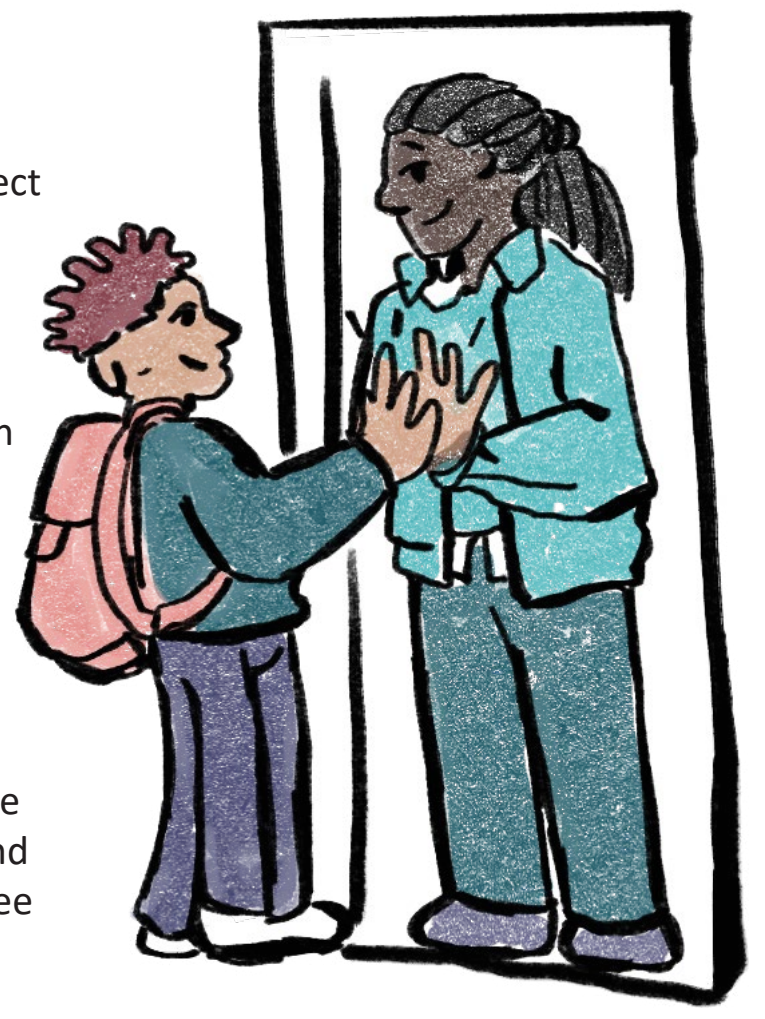


Grow-your-own (GYO) teaching and coaching programs are designed to recruit, train, and retain a diverse teaching pool, drawing from within school communities to increase racial, ethnic, and cultural diversity in schools, particularly in hard-to-staff fields like math and other STEM disciplines. Below, we highlight GYO programs founded to diversify and stabilize the teacher workforce in poverty-impacted schools. In Exhibit 5 and 6, we describe several projects that leverage youth and community members as resources - the Calculus Project's peer teacher component and two alternative pathways to teacher certification in the Boston Public Schools: (1) the Cadet program-which prepares students to support their peers in math learning while receiving competitive compensation as tutors, and (2) the Accelerated Community to Teacher Program which recruits eligible community members into an expedited teacher preparation track in their community schools.

The Calculus Project founder, Dr. Adrian Mims, describes the importance of diversifying the STEM pipeline:

“In today's world, economic access and full citizenship depend crucially on math and science literacy... closing racial and ethnic gaps is not only key to fulfilling the potential of people of color; it is also crucial to the well-being of our nation."

Future work should examine the longer-term impact of these pipeline programs on teacher retention and student outcomes.

\section{Exhibit 5. Innovation Spotlight: The Calculus Project's Peer Teacher Component}

The Calculus Project is a grassroots leadership initiative whose goal is to increase the number

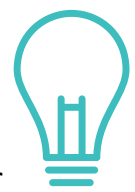
of students of color who enroll in AP Calculus in their senior year by supporting rigorous math instruction in grades 8 through 12. Additional math supports include summer preparatory classes, re-teaching, tutoring, and after-school study groups during the school year.

The peer teacher component of the project identifies students who are excellent peer teachers and pays them to work with teachers during the summer to teach younger peers. A subset of students have taken and passed the state educator licensure test for middle school while they were in high school and got jobs as tutors. Some of these students went on to become math teachers.

In reflecting on the initiative, founder Dr. Mims noted, "I just think we need to be bold and innovative and try to engage students early with the importance in the knowledge of mathematics."

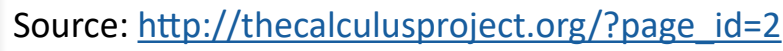

\section{Exhibit 6. Innovation Spotlight: Two Alternative Pathways to Teaching in the Boston Public Schools (BPS)}

\section{Teacher Cadet Program (TC)}

The Boston Public Schools (BPS) Teacher Cade (TC) program enlists culturally, racially, and linguistically diverse high school students in a program to prepare BPS high school students to be future educators through academic and leadership support. TC has partnered with the Young People's Project (YPP) to create opportunities for students to participate in academic enrichment, college readiness and workbased apprenticeships in grades 7-12, to enroll in undergraduate education programs, to become employed in BPS as summer teaching assistants, and to prepare them for licensure through prep courses so they can be considered as priority hiring candidates at BPS. The TC program leverages partnerships with local organizations, universities, and colleges to provide students with access to technology, networking with school administrators, and organized college visits. 


\section{Accelerated Community To Teacher Program (ACTT)}

The BPS ACTT Program draws on community assets to increase the number of top teachers in the district who reflect the racial, cultural and linguistic diversity of BPS students. The 12-month program is designed to prepare interested residents of the Boston community who hold a Bachelor's degree and have experience working with children in a classroom setting to become provisionally licensed educators. Candidates spend 12 months training with BPS teachers, preparing for the Massachusetts Tests for Educator Licensure (MTEL), and completing pre-practicum coursework while receiving a Sheltered English Immersion (SEI) endorsement course-an approach to teaching academic content to English learner students.

Source: https://www.teachboston.org/

\section{Call to Action}

- Funders: Support new teacher pipeline programs or the expansion of established programs including fellowships with a track record of success in

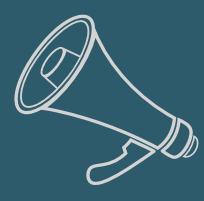
recruiting and retaining a diverse group of teachers with subject matter expertise

- Funders and policymakers: Explore opportunities to provide incentives for veteran math teachers and coaches to teach in poverty-impacted schools

- Researchers and academics: Rigorously evaluate long-term impact of these pipeline programs on teacher retention and student outcomes

\section{Practice-embedded Teacher Learning Models}

Teachers typically lack regular opportunities to observe model teaching practices. One math teacher leader and researcher described the lack of opportunities for observation in teaching:

\footnotetext{
"My instinct is that the fact that most teachers never see anyone teach besides themselves after they finish their training is just a recipe for getting teachers into ruts or into things that they don't see as ruts, but you do."
}

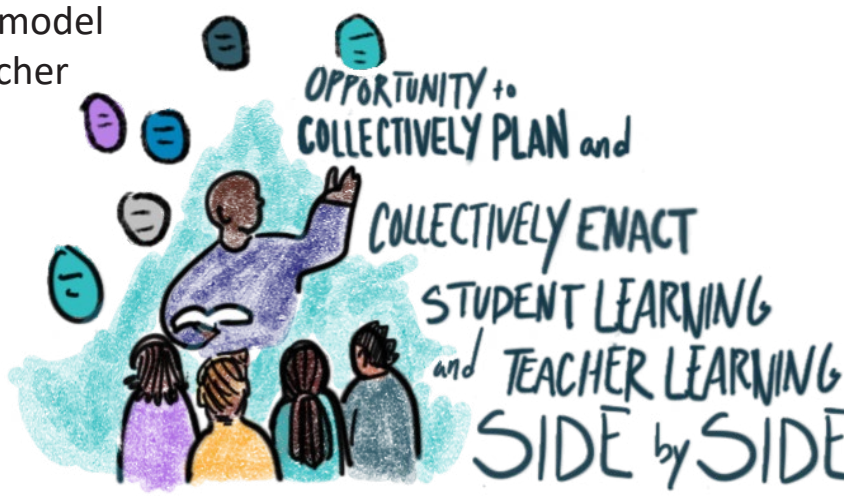

Since the onset of the practice-based teacher education movement in mathematics (e.g., Ball \& Forzani, 2011; Gibbons et al., 2017; Shaughnessy \& Boerst, 2018), the field has made progress in defining conditions for math teacher learning that provide teachers opportunities to collectively engage in the practice of ambitious teaching (Gibbons et al., 2021; University of Washington, n.d.). Math educators have also published guidelines for facilitators to prepare participants for embedded learning and promoting collaborative learning (Gibbons et al., 2021). These lessons should be shared, adapted, and tested at scale. 
The practice-based teacher education movement's influence in pre-service teacher education has gained significant traction. Through the examples below, we imagine how practice-based teacher education could be adapted at scale with inservice teachers. In Exhibit 7, we describe Math Labs-an example of what an effective model of embedded, practice-based instruction might look like in action.

\section{Exhibit 7. Innovation Spotlight: Math Labs as Embedded Professional Learning}

At the University of Washington College of Education, Math Labs-a subset of Learning

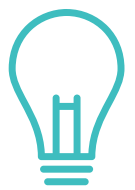
Labs-are a structure for job-embedded, collaborative, and practice-based teacher professional learning that takes place within the bounds of the school day. Math Lab learning cycles consist of four phases: learning together, co-planning a lesson, enacting the lesson together, and debriefing together.

In the Math Lab model, teachers have an opportunity to collectively plan, enact, and analyze a lesson. During that process, teachers anticipate likely student strategies and possible student responses. Teachers can "pause" the lesson through a "teacher time out" to decide how to respond to students' ideas as they emerge in the lesson. Key to this approach is the co-planning, co-enactment, and real-time reflection and intervention in the actual live classroom. An intended byproduct of this approach is the normalization of critical reflection of practice and continuous improvement.

Math Labs aim to promote a culture of collaboration and increase the capacity for educators to integrate new learning into their instruction.

Source: https://coetedd-wpengine.netdna-ssl.com/wp-content/uploads/2017/05/JMEL-Math-Labs-2018.pdf

\section{Call to Action}

- Administrators: Explore opportunities to implement and/or scale Math Labs and other practice-embedded models

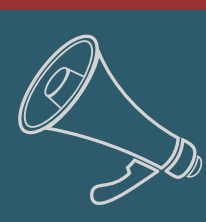

- Researchers and academics: Investigate the impact of practice-embedded models on teacher instructional practice and student math achievement

- Professional learning and advocacy organizations: Design guidebooks for school administrators, coaches, and teachers on the nuts and bolts of implementing a practice-embedded teacher learning model with guidance on scheduling, agendasetting, facilitating common planning time, enactment, and reflection 


\section{Digital Clinical Simulations ${ }^{1}$}

Research on developing expertise shows that opportunities for deliberate practice-focusing on specific skills and receiving feedback on performance-can substantially improve one's skill level (Ericsson, 2008). However, as we have noted above, teachers often do not have the chance to practice and receive feedback on teaching, particularly once they enter the profession (TNTP, 2015). Broadly speaking, education research shows that feedback on teaching can improve teacher's practice (Biancarosa et al., 2010; Kraft et al., 2018; Marsh et al., 2008), but the costs of scaling human feedback can be prohibitively high (Kraft et al., 2018).

In our increasingly virtual world-by choice and due to public health and climate crises-digital clinical simulations hold promise as a new space for math teacher professional learning that respond to these challenges. Simulations offer opportunities for individualized practice, a lower barrier for teachers to practice difficult skills in private, low-stress settings, opportunities for reflection and debrief, and have potential for scale. Digital clinical simulations have been used to help preservice (Kannan et al., 2018) and practicing math teachers (Anderson et al., 2020; Smith and Garrett, 2020) implement researchbased skills such as supporting students in communicating math understanding and reasoning. Recent research on digital simulations suggests that feedback and coaching during and after a simulation experience can improve preservice teacher performance (Cohen et al., 2020; Mikeska \& Howell, 2020). Work is underway to evaluate the impact of simulations on inservice teacher practice and student learning.

In Exhibits 8 and 9, we highlight two examples of simulations designed to improve teacher math learning through targeted practice in a lower stakes, simulated space. The future of math teacher learning should consider experimentation, adaptation, scaling and validating digital clinical simulations with additional teachers and establishing the link to change in teacher practice and student learning.

\section{Exhibit 8. Innovation Spotlight: Using "Teacher Moments" Mobile App to Foster Students' Positive Math Identities}

Teacher Moments is a mobile app that immerses teachers in multimedia vignettes of

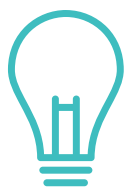
challenging classroom decisions (Thompson et al., 2019). Participants provide improvisational audio responses to scenarios involving students, parents or other school personnel. Responses are recorded for reflection, discussion, and expert feedback, and data can be analyzed by researchers for program evaluation purposes. Teacher Moments is generally built into a larger cycle of reflection and continuous improvement.

With the growing list of responsibilities that are placed on math teachers, helping students foster a strong mathematical identity is often pushed too far down the list. Teacher Moments presents math teachers with a range of scenarios that allows them to practice building a positive math culture in the classroom by navigating a small and whole group class "discussion" centered on an unstructured math task. Teachers are prompted to reflect on their choices within the app and in facilitated debrief and discussion with a coach or teacher educator.

Through a safe, simulated space, teachers practice discrete skills such as managing small and whole class discussions, as well as their sensibility in their discretionary space (Deborah Ball, AERA Presidential Address, 2018) before they have to implement a strategy in a classroom full of real students.

Source: https://tsl.mit.edu/practice space/teacher-moments/

\footnotetext{
${ }^{1}$ The MIT Teaching Systems Lab does innovation work in this area that is generously supported by the Bill \& Melinda Gates Foundation. One of the "Innovation Spotlights" featured in this section, Simulated Instruction in Mathematics Professional Development (SIM PD) is led by one of our advisory board members, although was selected by the study team independently of the advisory board member's feedback on earlier report drafts.
} 


\section{Exhibit 9. Innovation Spotlight: Simulated Instruction in Mathematics Professional Development (SIM PD)}

The SIM PD study helps teachers in grades 4-7 practice math questioning strategies focused on eliciting student understanding, asking them to explain their thinking and respond to their peer's mathematical thinking. In the simulated task, teachers must facilitate student discourse to promote engagement and understanding of math concepts.

Through SIM PD, teachers practice implementing these approaches in a mixed-reality classroom. That means that teachers use a computer to connect online while a trained simulation specialist, not visible to the teacher, operates student avatars in response to the actions of the teachers. Within each module, teachers participate in workshops, group and individual mixed-reality classroom practice sessions, and group debrief meetings. Participating teachers receive support and feedback from a coach and teacher colleagues.

Researchers examined the effect of SIM PD on teacher learning by randomly assigning 16 partner schools to receive the program or not. Among program participants, researchers detected improvement in instruction and teachers sustained instructional learning into the following school year. This holds promise for simulations as tools to help teachers practice ambitious instruction at scale.

Source: http://air.org/sites/default/files/SIM-PD-Study-Summary-April-2020.pdf

\section{Call to Action}

- Professional learning and advocacy organizations: Investigate digital clinical simulations for math teacher learning through experimentation,

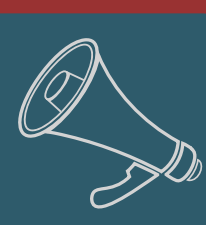
adaptation, scaling and validating with additional teachers

- Funders and policymakers: Explore the possibility of using digital clinical simulations for certification to offer more flexible options for prospective and inservice teachers

- Researchers: Establish a link between digital clinical simulation and changes in teacher practice and student learning 


\section{Transitioning Movements in Mathematics Education to Teacher Learning}

While math teacher learning might be in something of a "steady state," the field of math education is quite dynamic. One strategy for generating new ideas and innovation in math teacher learning might be to start from existing change movements in mathematics education. In our conversations with stakeholders, we were often surprised by the degree to which math education reform sometimes felt removed from improvements in math teacher learning. For instance, in a discussion of implementations of high-quality math curriculum as a reform strategy, one attendee in our virtual conference commented, "Ah yes, the three-day crash course in 'How to Teach' a new curriculum, right before school starts..." The push for a high quality curriculum, at least in this one district, did not include a commitment to teacher learning about the new curriculum. In our scan of math teacher professional learning, we identified at least two existing math learning movements that could be more explicitly and systematically transformed into teacher professional learning initiatives: (1) math for social justice, and (2) new course development and curriculum innovation.

\section{Professional Learning Initiatives Focusing on Equitable Mathematics}

One math instructional coach interviewee highlighted how critically important it is to keep instructional rigor at the center of any mathematics movement focused on equitable teaching practices. They stated, "there's no equity, there's no access, there's no liberation without the instructional core."

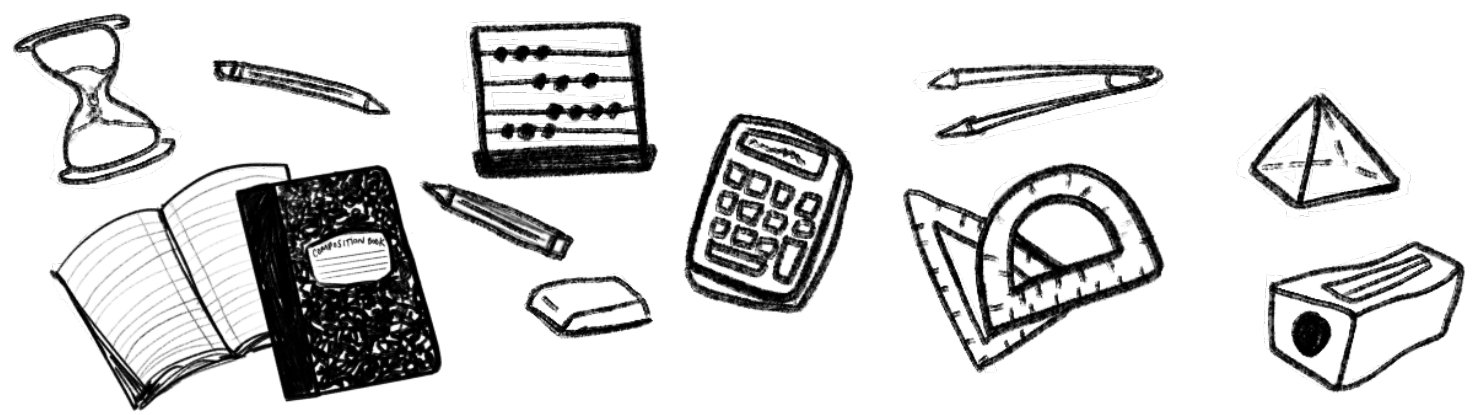

As the nation reckons with a long history of racial violence, injustice, and economic inequality, the increasingly widespread belief that math teachers have the "power to change the equation" for students' life outcomes is palpable among math educators (e.g., Benoit \& Reich, 2021). These views build on longstanding calls from the math education community for equitable teaching practices, high expectations, rigorous, rich, and relevant curricula, and building stronger community relationships (e.g., National Council of Teachers of Mathematics [NCTM], 2014; National Council of Supervisors of Mathematics [NCSM] and TODOS: Mathematics for ALL, 2016). Notable responses to these calls to action for high levels of mathematics literacy for all through include the Algebra Project, the Calculus Project, and Math for All, among others. 
In this domain, there is a deep and growing body of literature focused on: (1) use of curriculum materials to raise the critical consciousness of students through socially relevant mathematics (e.g., below, in New Course Development and Curriculum Innovation, we discuss one AP statistics teacher's Skew The Script curriculum based on real-world datasets about pressing social justice issues), (2) teacher instructional moves that intentionally build more rigorous and equitable mathematics classrooms by uprooting traditional notions of positionality and authority in the math classroom, and (3) teacher dispositions focusing on a range of productive orientations towards students such as asset framing - when a teacher sees the knowledge and skills that students possess as strengths, and resist framing differences between students in terms of "deficits" from an assumed norm or standard (Milner, 2010), and maintaining the expectation that all students can do rigorous math tasks.

New attention to the constant "micro moments" that teachers are faced with throughout the day-the improvisational interactions with students that present opportunities to "build students up" or to stifle them (AERA Presidential Address, 2018) - underscore the dynamic nature of the math classroom and the nuanced competencies required of teachers to support rigorous and equitable math instruction. Future teacher learning investments should help teachers anticipate and prepare for the dynamic nature of math classrooms.

Currently, the field of math teacher professional learning is ripe to translate the panacea of promising practices into a codified and systemic approach to teacher learning that can be tested against teacher practice and student learning. For example, if our goal is to support teachers in enacting ambitious instruction, teachers must: (1) have a reasonable idea of what that looks like in practice (instructional practice), and (2) believe that their students can manage rigorous tasks (teacher dispositions). Below, we show how equitable math principles can be linked to teacher learning action. We challenge the field to channel the energy around existing equitable math initiatives to build in additional concrete teacher learning components.

\section{Modeling Specific Equitable Math Teaching Practices in Action}

Many of the teaching practices underpinning the equitable mathematics movement hold promise for promoting all learners' math learning. Our field research suggests that it is not enough to merely tell teachers what must be done; the field has an obligation to show teachers what equitable instructional practices look like in action, across a range of contexts, how they might be adapted for individual students, and to support teachers in planning for these practices. For instance, as one district-embedded expert noted, good intentions and high expectations alone will not move the needle on student math achievement if the teacher does not know how to enact ambitious math instruction:

"All great, but if teachers have high expectations for kids, but they don't have any way of helping kids meet those expectations it's all for naught. And it's right now, where the level, I see so much of it, as berating practitioners are telling them, they got to pull their socks up, they got to have higher standards, but with absolutely zero specific advice, other than moral whipping. And I think if we're going to make any progress on these issues, we've got to drill down, again, to specific practices."

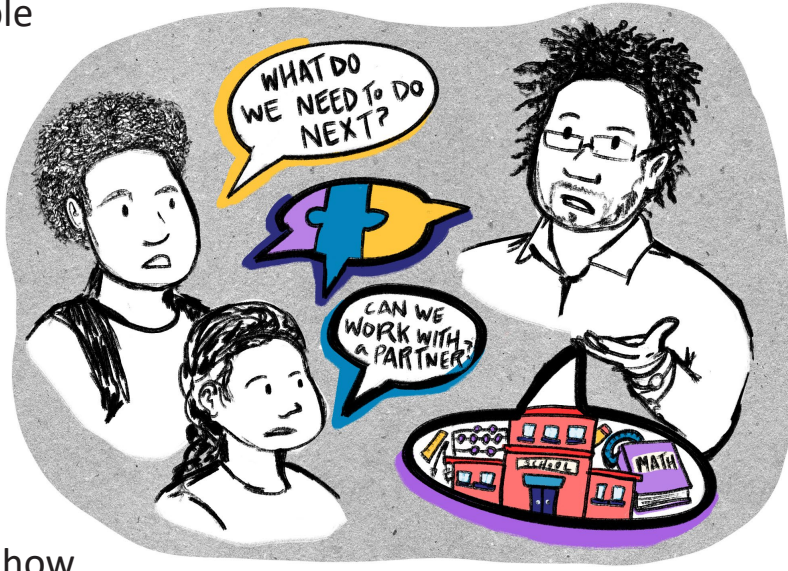


Above, we describe several teacher learning curricula rooted in this tradition through case studies and video libraries (e.g., Developing Mathematical Ideas) which may serve as models for future teacher learning initiatives focused on math for social justice.

\section{Helping Teachers See that their Students Can Manage Rigorous Tasks}

A second example of linking the movement for equitable mathematics to teacher learning is showing teachers that their students can thrive with rigorous instructional tasks.

A teacher's views of their student's math capabilities is a predictor of their student's math performance. Unfortunately, our research revealed that in many schools and classrooms, teachers "fundamentally believe rich problems are only good with the honors students" and that teachers don't always think that students who are struggling have the capability to tackle deep mathematics. Incorporating rich mathematics opportunities for all students-with a focus on showing teachers what that looks like in practice-allows students to demonstrate their mathematics knowledge, participate in classroom discourse, and develop a sense of mathematical identity. One math researcher and professional learning leader observed:

"Our experience is I think one of the most convincing things I hear from teachers often is that they give the kids a task that they think the kids can't do, and then they're blown away because the kids can do it. So that kind of thing can change minds about what their students are able to do, and then it's following that up and not letting that be a flash in the can moment in time."

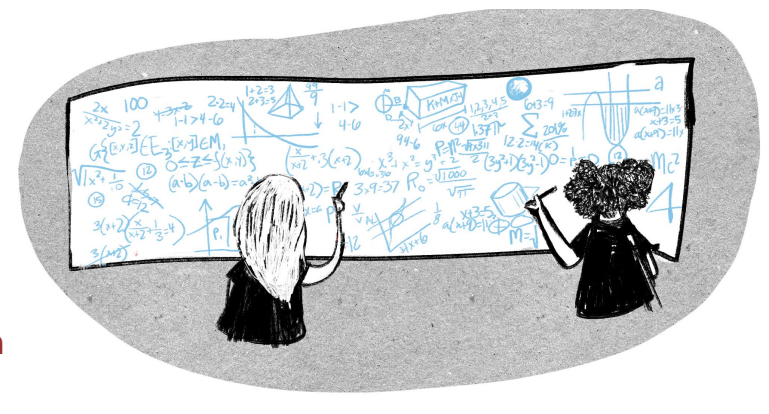

Teachers sometimes think of their students as a "blank slate" for knowledge transfer or delivery. This can be harmful to students when, for instance, they are placed in remedial math classes that focus on "tricks" to pass exams and standardized tests rather than high level conceptual thinking. The future of math teacher learning must support teachers in developing these skill sets through formal teacher learning curriculum (e.g., Exhibit 1), modeling, deliberate practice, and coaching. Curriculum should provide guidance for teachers to push high level conceptual thinking for struggling learners as well. In Exhibit 10, we tell the story of how Project QUASAR brought challenging math curricula to six poverty-impacted schools across the country.

\section{Exhibit 10. The Case of Raising Math Expectations}

In the 1990s, a project called QUASAR (Quantitative Understanding: Amplifying Student

Achievement and Reasoning) was created as an equity-focused curriculum striving for math instructional excellence. It brought enriching and challenging math curricula to six poverty-impacted schools across the country with the motivation that students in these schools were underperforming because they did not have access to grade-level math content and had not been pushed to solve complex math problems (Silver \& Lane, 1993).

This teaching approach was in sharp contrast to the focus on rote memorization of math facts and basic arithmetic that best described these students' math learning prior to participating in the program. Students participating in the program outperformed their classmates from similar backgrounds in other parts of the country on national assessments; student achievement soared particularly in the areas related to a deeper understanding of math and those that required students to solve open-ended problems - the exact focus areas of the QUASAR project. 
In the Call to Action box below, we outline several actionable strategies that can be the focus of related teacher professional learning programming.

\section{Call to Action}

Professional learning and advocacy organizations:

Convene leading groups and programs advocating for equity teaching in

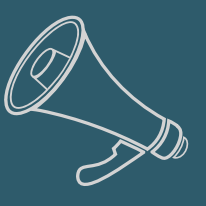
mathematics to focus on advancing their teacher learning strategies

Build programs that help teachers establish a view of equitable, ambitious teaching practice, shift their mindset towards what their students are capable of in mathematics, and document these practices and shifts

Design an open-source video library and "open classroom" projects to generate models of enactment of ambitious instruction with equitable teaching practices and curriculum in the math classroom

Funders:

Provide grants to schools and districts to create professional learning situated within school or district environments with a commitment to social justice

Design workshops to task established groups that focus on math for social justice to develop a theory of change and implementation plan for teacher learning

\section{New Course Development and Curriculum Innovation}

New K-12 math curriculum tracks like computational math and data science-particularly those that bring data to bear on real-world and community-oriented challenges-hold promise for simultaneously broadening participation in the future of work and moving math learning into the twenty-first century. When done well, data science integrates critical thinking, quantitative skills, and storytelling through numbers and supporting evidence (Rockmore, 2020).

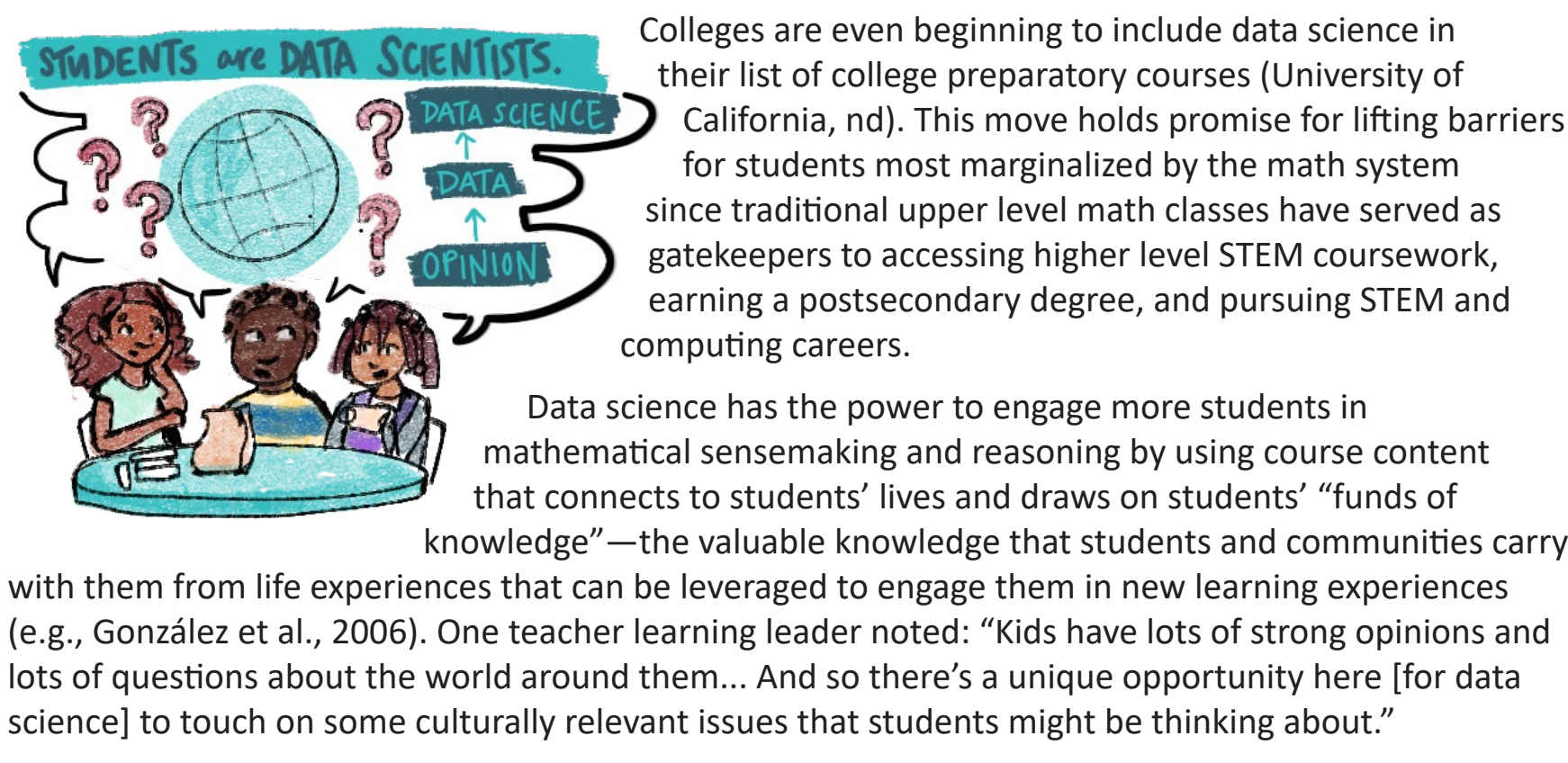


The challenge is that the field's understanding of how to support teachers in implementing these new courses is still emerging. An important contribution therefore, is for course and curriculum developers, administrators, and policymakers to pay careful attention to teacher learning components as they aim to bring data science to more students.

\section{Challenges And Opportunities For Teacher Preparation In Implementing New K-12 Data Science Curriculum}

Our research revealed significant teacher learning and preparation barriers to integrating computing and data science into mathematics disciplines. Our field work also revealed important opportunities for innovation.

The mainstream, at-scale integration of data science into $\mathrm{K}-12$ math curriculum is generally new territory, even though there are groups that have been working for a period of time to develop data science curriculum for the K-12 audience (e.g., youcubed, n.d.; Bootstrap, n.d.; Introduction to Data Science, n.d.; UT Dana Center). As such, the field is still wrestling with fundamental implementation questions such as-do we try to use math as a springboard for teachers to learn and teach data science curricula or do we teach it as a separate subject altogether? Experts suggest if data science is taught as a separate subject disconnected from math learning, it is easy for "both skills to remain brittle."

However, one challenge is that teachers often become accustomed to teaching in their discipline which may make it difficult to see the connections between computing and math. Further, teachers may need to build their content knowledge background in order to feel comfortable integrating computing into their instruction. Professional learning experiences should begin with understanding teachers' current math dispositions and knowledge and build from there.

A second challenge is that in many schools-particularly those under pressure to raise test scoreswhat is not tested is not taught. The on-the-ground reality is that if the content is not on the test, teachers report that it's going to be hard for them to "fit" data science into the curriculum. These pressures are even more pronounced in poverty-impacted schools that typically face more pressure to raise test scores. Due to these pressures, teachers and administrators are often so concerned with objectives and test scores that it is difficult for them to relax and consider the bigger pictures of mathematics.

A third challenge is teacher adoption of yet another new curriculum initiative. Teachers suggest that perhaps when they are involved in the planning, they will be more motivated to sustain new initiatives. One teacher that contributed to our field research noted:

"We've had a lot of things forced on us as teachers or headmasters, my colleagues and professionals and it latches on for one year. And then the next year we're onto the new thing. And it isn't until you're passionate about what you're doing and change the way you're doing the thing, that it can hold in integrating within the school."

Teachers are critically important in the design and implementation of new curricular initiatives. Yet, our conversations with leading voices in the field-including classroom teachers-highlighted that opportunities for innovative research and design are often limited to those within traditional spheres of academia.

As with the movement for greater attention to equity in math education, we see the movement for new computational curricula to be a dynamic corner of math education reform.

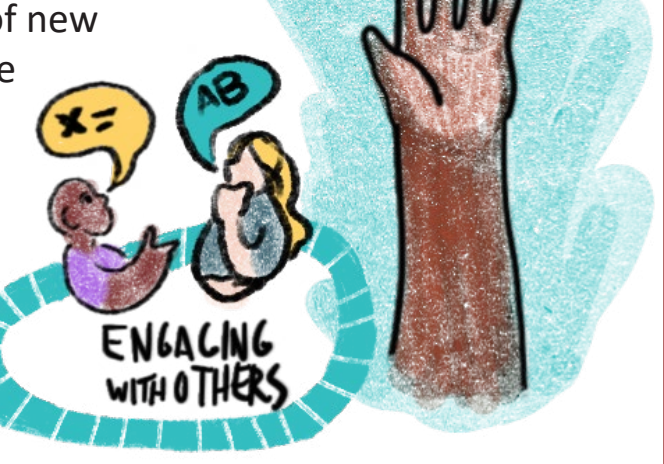


Naturally, leaders in this effort pour their attention into developing new curricula, but it may be possible to harness that energy and enthusiasm towards the question: how does teacher learning need to change for educators to feel well prepared to teach these new computational curricula?

Below, we provide a few examples of teachers who have taken real initiative in integrating data science into their math curricula, with very promising results for students most underestimated by the education system.

In Exhibits 11 and 12, we document examples of devoted teachers and professional learning organizations that have created new types of data science learning experiences for their students to increase engagement, make the math more relevant to their lives, and broaden the pool of students who see themselves as "math learners." One teacher in a poverty-impacted school noted, "Statistics is a vital course for our students. We are living in a big data society. That was their road in terms of all their options."

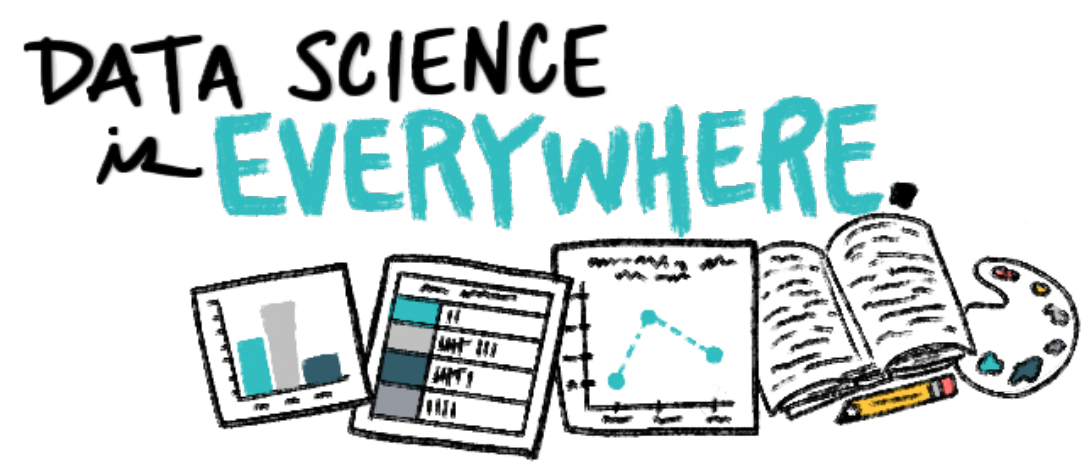

The programs highlighted below leverage social justice and other high-interest issues to pique students' natural curiosity and desire to understand their world, and help them use data to advocate for a better world.

\section{Exhibit 11. Innovation Spotlight: Skew The Script: AP Statistics Reimagined}

An AP statistics teacher was tired of their students' disengagement with typical textbook statistics problems like the time it takes to fill up a swimming pool of a certain volume or the correlation between hand width and height. This disengagement resulted in students learning statistics at a shallow level, leaving school unprepared to apply quantitative reasoning to "messy problems of the real world."

In response, they built an open-source AP Statistics curriculum grounded in real world math problems with social relevance at their core. The curriculum is grounded in datasets on deep social issues such as "Police Use of Force \& Race" and "Flint City Officials' Water Cover Up" to light-hearted topics like "How to *Not* Make Money in Vegas" and "Who is Better: LeBron or Jordan?" Each topic has an associated statistical objective.

The data speak for themselves: With the new curriculum, the students at the founding teacher's school passed the AP Statistics exam at higher numbers in that one year than in the previous 16 years combinedthe highest pass rate that the district had seen at a neighborhood school in the last decade. The teacher's International Baccalaureate (IB) students had the highest pass rate on the IB Math Studies exam in district history. The program's founder attributed these gains to student engagement, noting, "we make math what it already is: relevant."

Sources: https://skewthescript.org/about https://skewthescript.org/highlights 
Exhibit 12. Innovation Spotlight: Integrated Computing for Algebra, Physics and Data Science For All Students through Bootstrap

Bootstrap works with states and districts across the country, supporting tens of thousands of students each year-including a majority of learners from underrepresented backgrounds in STEM-in the integration of computing into STEM courses like math, physics, social studies, history, and more.

Teachers attend professional learning workshops that help them deliver content such as:

- Algebra: a module that integrates programming and algebraic concepts into a standard math class to create a video game.

- Data Science: a module that encourages students to form their own questions about the world around them, and analyze data critically and carefully to find the answers. This module is used by science, statistics, and history teachers, in addition to conventional computer science (CS) teachers.

- Physics: a module that uses computer programming and modeling to help students understand dynamics concepts and build models of the physical world.

- Reactive: a module that digs deeper into programming and allows students to build more sophisticated computer programs by building on previous Bootstrap modules. Students explore animation, data structures, and processing user input.

Through research-based curricular modules for grades 6-12, the Bootstrap material aims to reinforce core concepts in math and other STEM disciplines, which support non-CS teachers in adopting rigorous and engaging computing content.

Sources: https://bootstrapworld.org/

\section{Call to Action}

- Professional learning and advocacy organizations and funders:

Convene developers of new computational math curriculum to focus on

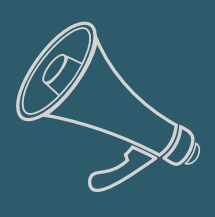

incorporating richer teacher learning strategies into their theories of change

Solicit development proposals from educators to design new K-12 data science curricular tracks that integrate computation and math grounded in real-world and community challenges

- Administer grants to teachers to develop new data science courses and develop a set of accompanying open-source materials

- Funders, researchers, and academics: Fund evaluations of more established data science programs that integrate mathematics to understand their impact on teacher and student learning outcomes

- Administrators: Consider how to meaningfully capture student learning in data science, possibly through portfolio or capstone projects 


\section{Investing in the Future of Math Teacher Professional Learning}

In our landscape scan, we identified three crucial features of the current condition of math teacher learning: (1) complacency with well-established interventions which have limited evidence of change in student math learning, (2) pockets of interesting work but an overall sparse level of experimentation and innovation and (3) dynamic movements in math education that should be challenged to explicitly address teacher learning. As a field, we must continuously challenge ourselves with this question:

"If we are to teach students differently, how must we prepare teachers differently?"

In this section, we reiterate some of our core findings and reflect on what conversations might be missing from the dialogue.

First, math teacher learning is in a "steady state," probably best understood as an unacceptable level of complacency rather than a satisfactory baseline. Three kinds of professional learning practices dominate the steady state: PLCs, coaching, and building teachers' content knowledge. Given the longevity and ubiquity of these professional learning streams, we had high expectations for a strong link to improved math teaching and learning. Yet, despite the tenet in math education that higher quality mathematics teaching translates into better student outcomes, even the most rigorous studies of teacher content learning have not been able to link improvements in teacher's math practice to better student math learning (e.g., Garet et al., 2008; Garet et al., 2016; Jacob et al., 2017; Kraft \& Hill, 2020). Cracking this enigma should be a top priority for the field.

In the case of PLCs, which are widespread and have good face validity-teachers appreciate the chance to connect with colleagues about practice-there is no strong evidence between participating in PLCs and student math learning. This finding may be less surprising; scholars remind us that PLCs are diffuse and generally do not follow a particular model, structure, or instructional focus. Thus, recommendations related to PLCs and content learning challenge the field to develop a theory of action for better understanding the translation of teacher learning to instructional practice and student learning. If we are to revitalize the PLC, we must start by bringing structure and focus to a widespread, diffuse phenomena through convenings of a diverse group of math educators.

Recommendations related to instructional coaching-whose link to student achievement is slightly better established (Campbell \& Malkus, 2011; Kraft et al., 2018)—should explore more scalable math coaching models such as web-based models. Coaching academies to proliferate web-based models or "telecoaching" might also help meet the shortage of highly-skilled math coaches-which scholars deem necessary to address the intensive work needed to develop teachers' ambitious instructional practice.

While the three steady state components appear insufficient in isolation, there is some evidence that "surges" of well-funded, comprehensive applications of coaching, workshops, and PLCs can lead to student math learning gains, at least while the funding is maintained. A change strategy related to systemic intervention might begin by funding studies to understand mechanisms that support sustainability of interventions and by engaging the business, tech, and national security sectors in viewing math teacher learning as an equity, competitiveness, and security issue.

Second, beyond this steady state, the landscape of math teacher learning innovation is sparse. We identified several innovations on the horizon-online teacher learning communities, grow-your-own pipelines, practice based teacher education, and digital clinical simulations - that could become a more standard part of math teacher learning systems in the years ahead. 
These initiatives are individually interesting, but it does not appear to be a time of extensive experimentation and innovation across in-service math teacher learning. Recommendations related to teacher learning innovations include seed funding to expand innovation, but also rigorous studies to better understand the role of teacher professional learning pathways in diversifying, strengthening, and stabilizing the teacher pipeline. The field stands to learn more about the impact of diverse professional learning formats (asynchronous, school-embedded, simulation-based) on teacher outcomes such as equitable math practice, content learning, job satisfaction, and retention.

Third, while math teacher learning may be in a steady state, we identified many dynamic movements in math education that we challenge to develop an explicit teacher learning model. Math education initiatives focused on equitable mathematics and new course development and curriculum innovation are two examples of movements with considerable traction. These movements offer new practices, instructional activities, and curriculum resources for math teachers. However, our funding recommendation challenges these groups to make math teacher learning a focal area in their theories of change. Programs that help teachers enact ambitious instructional practice through models and supports them in implementing rigorous and relevant instructional tasks would move teacher learning forward.

Recommendations for the future of math teacher learning are best summarized as four streams:

1. Targeted investments to revitalize specific features of the "steady state" such as PLCS, instructional coaching, and content-interventions

2. Investments in advocacy, school and district leadership training, and research to reenergize and re-evaluate "steady-state" suite of approaches

3. Use of small-stage seed funds to increase experimentation and innovation in the field to generate new thinking and practice and launch initiatives that could ultimately supplement or replace steady state approaches, and

4. Targeted investments in important math education reform efforts-such as new courses for a computational work or the surge of interest in equitable math educationto encourage these important movements to engage math teacher learning in their theory of change.

Threaded throughout this report were "calls to action" boxes which offered targeted suggestions for different education stakeholder groups. Below, we reflect on important criticisms of the report and how they might be addressed in future work.

\section{Reflections on What May Be Missing from the Conversation}

We are grateful for the feedback of several "critical friends" in the field who raised some important criticisms of this report and its framing. These commentators argued that our report had insufficient attention to issues of equity and structural inequality throughout, and in particular to deep-seated structural issues such as how we organize schools for learning, how teachers are viewed as professionals, how the work lives of teachers are organized, and how many schools and systems perpetuate deficit views of teachers and students. One version of this critique might be that in this report we discuss how math teacher learning could be improved given the current state of mathematics education, but another powerful look at this topic would reimagine mathematics education to create a richer platform for rethinking math teacher learning. 
We believe that this critique is fair. Our sponsors asked us to investigate math teacher learning, and we composed a series of questions that asked about the current state of math teacher learning and the future of math teacher learning, and those questions implicitly assume a kind of stability in mathematics education. Thus, our interviews did not explicitly invite our respondents to re-envision math mathematics education in the context of math teacher learning.

Thus, we can say, on the one hand, that in our interview transcripts and convening discussions our respondents largely confined their responses to the specific questions we asked. As a result, our report has a kind of inherent, implicit conservatism: "given the world of mathematics education we live in, what can we do to improve teacher learning?" On the other hand, when we posed these questions, respondents generally accepted the terms of the question, and they did not insist that we step back to consider these deeper structural issues. Presumably, for at least some of our respondents, the kinds of tactical questions that we posed did not need to be entirely subsumed by more strategic concerns.

These criticisms lead to an important caveat to our findings and recommendations. Our findings and recommendations assume that math teaching will continue to be iteratively improved, but not fundamentally reconstructed through a liberatory lens in the near term. It would be a productive exercise to return to our stakeholders, ask them to reimagine a better, more equitable future for math education, and then ask our respondents to imagine the kind of math teacher learning that would be required for such a transformation. It would be quite interesting to learn if such a framing leads to different kinds of visions for the future of math teacher learning.

\section{Conclusion}

Through engagement with education stakeholders at all levels, we call on the field to view teacher learning as a multi-faceted challenge-to which we already have many solutions - but with varying levels of evidence, financial support on the part of districts, and teacher and leadership buy-in. Meaningfully engaging multi-sector partners, district leadership, and educators in the investment process will increase the likelihood that the next generation of teacher learning efforts will be innovative, impactful, and sustainable. 


\section{Acknowledgments}

The INSPIRE-Math team of the MIT Teaching Systems Lab (MIT TSL) is grateful for the contributions of many individuals whose ideas and work shaped this report. The content of this report is grounded in the perspectives of a multitude of voices in math teacher professional learning: interviews with math researchers, teachers, teacher leaders, and publishers; participation of panelists and audience members in a recent virtual conference, The Future of Math Teacher Professional Learning; guidance from the project advisory board; and a review of secondary sources. We are also grateful for the extraordinary research support of the MIT undergraduate research assistants working on the project, Dasha Castillo, Emily Zhang, Rishi Kommalapati, Isy Osubor, Christina Warren, Luly Torres, Aileen Han, and Mario Peraza; event hosting support of Jessica Rondon (MIT TSL), Kate Wilson Somers of RisingT media, Garrett Beazley (MIT TSL), graphic recording artists Haley McDevitt and Kay Dugan Murrell, and the American Sign Language interpreters and close-captioners who helped make the content in our virtual conference accessible to more community members.

We would like to acknowledge the intellectual contributions of our Advisory Board members: Linda Ruiz Davenport, Suzanne Chapin, Rachel Garrett, Gregory Larnell, and Jon Star. We are also grateful for the many "critical friend" reviewers who provided invaluable insight and feedback on this report.

We are grateful to Bill \& Melinda Gates Foundation for their continued support and for providing us this opportunity to inform the field on recommendations for the future of math teacher professional learning in service of all our nation's learners.

This report is based on research funded by the Bill \& Melinda Gates Foundation. The findings and conclusions contained within are those of the authors and do not necessarily reflect positions or policies of the Bill \& Melinda Gates Foundation. 


\section{References}

About the Program. (2021). The Robert Noyce Teacher Scholarship Program. https://www.nsfnoyce.org/about/

AERA 2018 Presidential Address: Deborah Loewenberg Ball. (2018, April 15).

https://www.youtube.com/watch?v=JGzQ70 SIYY

Anderson, N., Slama, R., Moussapour, R. M., Benoit, G., \& Reich, J. (2020). Using digital clinical simulations and authoring tools to support teachers in eliciting learners' mathematical knowledge (Proceedings of the 2020 Connected Learning Summit, pp. 11-19). Carnegie Mellon University. https://2020.connectedlearningsummit.org/proceedings/

Ball, D. L., \& Forzani, F. M. (2011). Building a common core for learning to teach: And connecting professional learning to practice. American Educator, 35(2), 17-21, 38-39.

Benoit, G., \& Reich, J. (2021, January 27). The power to change the equation: Mathematics teacher learning reimagined. Prepared for the Future of Math Teacher Professional Learning Provocation Series. https://tsl.mit.edu/the-power-to-change-theequation-mathematics-teacher-learning-reimagined/

Biancarosa, G., Bryk, A. S., \& Dexter, E. R. (2010). Assessing the value-added effects of literacy collaborative professional development on student learning. The Elementary School Journal, 111(1), 7-34. https://doi.org/10.1086/653468

Boyd, D., Lankford, H., Loeb, S., Rockoff, J., \& Wyckoff, J. (2008). The narrowing gap in New York City teacher qualifications and its implications for student achievement in high-poverty schools (No. 14021; NBER Working Paper Series).

Brown, T. (2017). Teachers' voices are regularly absent from conversations about their professional growth.

Campbell, P. F., \& Malkus, N. N. (2011). The impact of elementary mathematics coaches on student achievement. The Elementary School Journal, 111(3), 430-454. https://doi.org/10.1086/657654

Carver-Thomas, D., \& Darling-Hammond, L. (2017). Teacher turnover: Why it matters and what we can do about it. Learning Policy Institute.

Chapin, S. H., \& O'Connor, C. (2004). Project challenge: Identifying and developing talent in mathematics within low-income urban schools. Boston University School of Education, Research Report No. 1.

Cohen, J., Wong, V., Krishnamachari, A., \& Berlin, R. (2020). Teacher coaching in a simulated environment. Educational Evaluation and Policy Analysis, 42(2), 208-231. https://doi.org/10.3102/0162373720906217

Common Core State Standards for Mathematics. (2010). Common Core State Standards Initiative. http://www.corestandards.org

Curriculum and evaluation standards for school mathematics. (1989). National Council of Teachers of Mathematics.

Dee, T. S., \& Goldhaber, D. (2017). Understanding and addressing teacher shortages in the United States. The Hamilton Project, Brookings.

Desimone, L. M. (2009). Improving impact studies of teachers' professional development: Toward better conceptualizations and measures. Educational Researcher, 38(3), 181-199. https://doi.org/10.3102/0013189X08331140

Diamond, J. B. (2007). Where the rubber meets the road: Rethinking the connection between high-stakes testing policy and classroom instruction. Sociology of Education, 80(4), 285-313. https://doi.org/10.1177/003804070708000401

DuFour, R. (2004). What is a professional learning community? Educational Leadership, 61(8).

Ericsson, K. A. (2008). Deliberate practice and acquisition of expert performance: A general overview. Academic Emergency Medicine, 15(11), 988-994. https://doi.org/10.1111/j.1553-2712.2008.00227.x

Garet, M. S., Heppen, J. B., Walters, K., Parkinson, J., Smith, T. M., Song, M., Garrett, R., Yang, R., \& Borman, G. D. (2016). Focusing on mathematical knowledge: The impact of content-intensive teacher professional development (NCEE 2016-4010). National Center for Education Evaluation and Regional Assistance, Institute of Education Sciences, U.S. Department of Education.

Garet, M. S., Wayne, A. J., Stancavage, F., Taylor, J., Eaton, M., Walters, K., . . Doolittle, F. (2011). Middle school mathematics professional development impact study: Findings after the second year of implementation (NCEE 2011-4024). Washington, DC: National Center for Education Evaluation, Institute of Education Sciences, U.S. Department of Education. 
Gibbons, L. K., \& Cobb, P. (2016). Content-focused coaching: Five key practices. The Elementary School Journal, 117(2), 237-260. https://doi.org/10.1086/688906

Gibbons, L. K., Kazemi, E., Hintz, A., \& Hartmann, E. (2017). Teacher time out: Educators learning together in and through practice. NCSM Journal of Mathematics Education Leadership, 18(2), 28-46.

Gibbons, L. K., Lewis, R. M., Nieman, H., \& Resnick, A. F. (2021). Conceptualizing the work of facilitating practice-embedded teacher learning. Teaching and Teacher Education, 101, 103304. https://doi.org/10.1016/i.tate.2021.103304

Global Math Department. (2020, June 2). Global Math Department. http://globalmathdepartment.org

Goldhaber, D., Theobald, R., \& Tien, C. (2019). Why we need a diverse teacher workforce. Phi Delta Kappan, 100(5), 25-30.

González, N., Moll, L. C., \& Amanti, C. (Eds.). (2005). Funds of knowledge: Theorizing practice in households, communities, and classrooms. L. Erlbaum Associates.

Grant, C. M., \& Davenport, L. R. (2009). Principals in partnership with math coaches. Principal, 88(5), 36-41.

Grassroots Workshops. (2019). https://grassrootsworkshops.com/workshops

Hendrickson, K. (2016). Math teachers' circles: The effects of a professional development community on mathematics teachers' identities [Dissertation]. Ohio University.

Hill, H. C. (2021, February 4). After 30 years of reforms to improve math instruction, reasons for hope and dismay. Brookings. https://www.brookings.edu/blog/brown-center-chalkboard/2021/02/04/after-30-years-of-reforms-to-improvemath-instruction-reasons-for-hope-and-dismay/

Hill, H. C., Rowan, B., \& Ball, D. L. (2005). Effects of teachers' mathematical knowledge for teaching on student achievement. American Educational Research Journal, 42(2), 371-406. https://doi.org/10.3102/00028312042002371

Integrated computing for algebra, physics and data science, for all students. (n.d.). Bootstrap.

https://bootstrapworld.org

Introduction to Data Science. (2021). IDS. https://www.introdatascience.org

Jacob, R., Hill, H., \& Corey, D. (2017). The impact of a professional development program on teachers' mathematical knowledge for teaching, instruction, and student achievement. Journal of Research on Educational Effectiveness, 10(2), 379-407. https://doi.org/10.1080/19345747.2016.1273411

Jacobs, V. R., Lamb, L. L. C., \& Philipp, R. A. (2010). Professional noticing of children's mathematical thinking. Journal for Research in Mathematics Education, 41(2), 169-202.

Kannan, P., Zapata-Rivera, D., Mikeska, J., Bryant, A., Long, R., \& Howell, H. (2018). Providing formative feedback to preservice teachers as they practice facilitation of high-quality discussions in simulated mathematics and science methods classrooms (Proceedings of Society for Information Technology \& Teacher Education International Conference, pp. 1570-1575).

Kraft, M. A., Blazar, D., \& Hogan, D. (2018). The effect of teacher coaching on instruction and achievement: A meta-analysis of the causal evidence. Review of Educational Research, 88(4), 547-588. https://doi. org/10.3102/0034654318759268

Kraft, M. A., \& Hill, H. C. (2020). Developing ambitious mathematics instruction through web-based coaching: A randomized field trial. American Educational Research Journal, 57(6), 2378-2414. https://doi.org/10.3102/0002831220916840

Launch Years | UT Dana Center. (n.d.). The University of Texas Dana Center. Retrieved April 30, 2021, from https://www. utdanacenter.org/our-work/k-12-education/launch-years

Learning Labs: A design for job-embedded professional development. (2014). Teacher Education by Design. http://tedd.org/ learning-labs

Marle, P., Khaliqi, D., \& Lisa, D. (2012). An inquiry into Math Teachers' Circle: Findings from two year-long cohorts. University of Colorado Springs.

Marsh, J. A., McCombs, J. S., Lockwood, J. R., Martorell, F., Gershwin, D., Naftel, S., Le, V., Shea, M., Barney, H., \& Crego, A. (2008). Supporting literacy across the sunshine state: A study of Florida middle school reading coaches.

Math Teachers' Circle Network. (2021). https://www.mathteacherscircle.org/about/what-is-a-math-teachers-circle/ 
Mikeska, J. N., \& Howell, H. (2020). Simulations as practice-based spaces to support elementary teachers in learning how to facilitate argumentation-focused science discussions. Journal of Research in Science Teaching, 57(9), 1356-1399. https://doi.org/10.1002/tea.21659

Milner, H. R. (2010). Start where you are, but don't stay there: Understanding diversity, opportunity gaps, and teaching in today's classrooms. Harvard Education Press.

National Council of Supervisors of Mathematics (NCSM), \& TODOS: Mathematics for ALL. (2016). Mathematics education through the lens of social justice: Acknowledgment, actions, and accountability. https://www. todos-math.org/assets/docs2016/2016Enews/3.pospaper16 wtodos_8pp.pdf

National Council of Teachers of Mathematics (Ed.). (2014). Principles to actions: Ensuring mathematical success for all. NCTM, National Council of Teachers of Mathematics.

Reich, J., \& Mehta, J. (2021, July 21). Healing, Community, and Humanity: How Students and Teachers Want to Reinvent Schools Post-COVID. https://doi.org/10.35542/osf.io/nd52b

Rockmore, D. (2020). Is it time to kill calculus? https://www.salon.com/2020/09/26/teaching-data-science-instead-ofcalculus-high-schools-math-debate/

Russell, J. L., Correnti, R., Stein, M. K., Thomas, A., Bill, V., \& Speranzo, L. (2020). Mathematics coaching for conceptual understanding: Promising evidence regarding the Tennessee math coaching model. Educational Evaluation and Policy Analysis, 42(3), 439-466. https://doi.org/10.3102/0162373720940699

Shaughnessy, M., \& Boerst, T. A. (2018). Uncovering the skills that preservice teachers bring to teacher education: The practice of eliciting a student's thinking. Journal of Teacher Education, 69(1), 40-55. https://doi. org/10.1177/0022487117702574

Silver, E. A., \& Lane, S. (1993). Assessment in the context of mathematics instruction reform: The design of assessment in the QUASAR project. In M. Niss (Ed.), Cases of Assessment in Mathematics Education (Vol. 1, pp. 59-69). Springer Netherlands. https://doi.org/10.1007/978-94-017-0980-4 6

Silver, E. A., \& Stein, M. K. (1996). The QUASAR project: The "revolution of the possible" in mathematics instructional reform in urban middle schools. Urban Education, 30(4), 476-521. https://doi. org/10.1177/0042085996030004006

Slama, R., Reich, J., \& Anderson, N. (2021, January 28). Let's hit the refresh button (a couple of times): Reimagining math curriculum and teacher learning to broaden participation in the math of the future.

Smith, T. M., \& Garrett, R. (2020). SIM PD Study. American Institutes for Research. https://www.air.org/sites/default/ files/SIM-PD-Study-Summary-April-2020.pdf

Snapshot. (n.d.). Retrieved April 30, 2021, from https://www.utdanacenter.org/our-work/k-12-education/launch-years

Teacher Cadet Program. (2019). TeachBoston. https://www.teachboston.org/hstt

The Calculus Project. (n.d.). The Calculus Project. http://thecalculusproject.org/?page id=2

Thompson, M., Owho-Ovuakporie, K., Robinson, K., Kim, Y. J., Slama, R., \& Reich, J. (2019). Teacher Moments: A digital simulation for preservice teachers to approximate parent-teacher conversations. Journal of Digital Learning in Teacher Education, 35(3), 144-164. https://doi.org/10.1080/21532974.2019.1587727

TNTP. (2015). The mirage: Confronting the hard truth about our quest for teacher development.

University of California A-G Policy Resource Guide. (n.d.). UCOP. https://hs-articulation.ucop.edu/guide/newsresources/announcements/

White, D., Donaldson, B., Hodge, A., \& Ruff, A. (2013). Examining the effects of Math Teachers' Circles on aspects of teachers' mathematical knowledge for teaching. International Journal for Mathematics Teaching and Learning. http://www.cimt.org.uk

Youcubed K-12 Data Science. (n.d.). Youcubed. https://www.youcubed.org/resource/data-literacy/

Young-Saver, D. (2020). Skew The Script. Skew The Script. https://skewthescript.org/about 